\title{
Vibration of Antisymmetric Angle-Ply Laminated Plates of Higher-Order Theory with Variable Thickness
}

\author{
A. K. Nor Hafizah, ${ }^{1,2}$ J. H. Lee, ${ }^{3}$ Z. A. Aziz, ${ }^{1,2}$ and K. K. Viswanathan ${ }^{2,4}$ \\ ${ }^{1}$ Department of Mathematical Sciences, Faculty of Science, Universiti Teknologi Malaysia, Skudai, 81310 Johor Bahru, Johor, Malaysia \\ ${ }^{2}$ UTM Centre for Industrial and Applied Mathematics, Ibnu Sina Institute for Scientific \& Industrial Research, \\ Universiti Teknologi Malaysia, Skudai, 81310 Johor Bahru, Johor, Malaysia \\ ${ }^{3}$ Department of Naval Architecture and Ocean Engineering, Inha University, 100 Inharo, Nam-gu, Incheon 22212, Republic of Korea \\ ${ }^{4}$ Kuwait College of Science and Technology, Doha District, Block 4, P.O. Box 27235, 13133 Safat, Kuwait
}

Correspondence should be addressed to K. K. Viswanathan; visu20@yahoo.com

Received 6 December 2017; Revised 15 February 2018; Accepted 27 March 2018; Published 7 May 2018

Academic Editor: Francesco Aymerich

Copyright (C) 2018 A. K. Nor Hafizah et al. This is an open access article distributed under the Creative Commons Attribution License, which permits unrestricted use, distribution, and reproduction in any medium, provided the original work is properly cited.

\begin{abstract}
Free vibration of antisymmetric angle-ply laminated plates with variable thickness is studied. Higher-order shear deformation plate theory (HSDT) is introduced in the present method to remove the shear correction factors and improve the accuracy of transverse shear stresses. The thickness variations are assumed to be linear, exponential, and sinusoidal. The coupled differential equations are obtained in terms of displacement and rotational functions and approximated using cubic and quantic spline. A generalized eigenvalue problem is obtained and solved numerically by employing the eigensolution techniques with eigenvectors as spline coefficients to obtain the required frequencies. The results of numerical calculations are presented for laminated plates with simply supported boundary conditions. Comparisons of the current solutions and those reported in literature are provided to verify the accuracy of the proposed method. The effects of aspect ratio, number of layers, ply-angles, side-to-thickness ratio, and materials on the free vibration of cylindrical plates are discussed in detail.
\end{abstract}

\section{Introduction}

A composite is a material that consists of two or more constituent materials. Composite structures are widely used in structural applications because of their advantage properties such as having high strength-to-weight ratios, being lightweight, and having higher specific stiffness-to-weight ratio. Classical theory was developed originally based on the Love-Kirchoff assumption for thin elastic shells where transverse effects are neglected [1]. Therefore, refinements to Love's first approximation theory of thin elastic shell were developed by Reissner [2] and Mindlin [3]. The most significant difference between the classical and shear deformation theories is the effect of including transverse shear deformation on the predicted deflections and frequencies [4]. As for the first-order shear deformation theory (FSDT), the theory extends the kinematics of the classical shell theory (CST) by relaxing the normality restriction and allowing for arbitrary but constant rotation of transverse normals. However FSDT requires the usage of shear correction factor in order to satisfy zero shear conditions on the top and bottom surfaces of the plate, which is considered a shortcoming of this theory. To overcome the limitation of FSDT, higher-order deformation theory which considers shear effect without any necessity to use shear correction factors was proposed [5]. HSDT further relaxes the kinematic hypothesis by removing the straightness assumption where the straight normal to the middle plane before deformation may become cubic curves after deformation [6]. According to Reddy [4], higherorder theories can represent the kinematics better, may not require shear correction factors, and can yield more accurate interlaminar stress distributions.

The study on HSDT for vibration analysis of shells had been conducted by a few researchers. Xiaoping and Liangxin [7] used Fourier series method to investigate vibration of symmetric cross-ply plates. A Navier solution 
was developed by Adim et al. [8] and Kumar et al. [9] to analyse vibration of symmetric and antisymmetric crossply laminates with simply supported boundary conditions. Ritz method was proposed by Hanna and Leissa [10] to study the vibration of completely free rectangular plate. Zuo et al. [11] presented the method of wavelet finite element method for vibration analysis of symmetric and antisymmetric cross-ply/angle-ply laminated composite plates under simply supported boundary conditions. The B-spline wavelet scaling functions were employed as approximating functions of the method of wavelet finite element. Dynamic analysis of multilayer symmetric composite plates was conducted by [12] Mallikarjuna and Kant [12, 13] by using a simple isoparametric finite element formulation based on a higherorder displacement model with an explicit time marching scheme. Using the same method, they studied the vibration of unsymmetrically laminated composite and sandwich plates. Simply supported and clamped boundary conditions were considered in both studies. Zhang and Selim [14] studied the vibration of carbon nanotube (CNT) reinforced functionally graded thick laminated composite plates. The element-free IMLS-Ritz method was employed for the solution of the problem and further utilizing the Mori-Tanaka approach for estimating the effective material properties of the composite. Saira et al. [15] investigated free vibration of antisymmetric angle-ply laminated plates using higher-order theory under simply supported boundary conditions. Constant thickness was considered in the study.

Bouazza et al. [16] have presented vibration behaviour of laminated composite simply supported rectangular plates using a closed form solution of Navier method. [17] D. B. Singh and B. N. Singh [17] have proposed Trigonometric Deformation Theory (TDT) and Trigonometric-Hyperbolic Deformation Theory (THDT) for the analysis of laminated and three-dimensional braided composite plate using FEM solution. The results were obtained with two types of boundary condition, that is, all edges simply supported and all edges clamped boundary conditions. Zamani et al. [18] developed direct viscoelastic approach to investigate the dynamic behaviour of thick polymer-matrix composite plates on viscoPasternak foundation. Both symmetry and antisymmetric plates are considered in the research. The study on vibration of simply supported functionally graded plates using HSDT has been conducted by Thai and Kim [19] and Thinh et al. [20]. The solutions were assumed using Navier approach. Vibration analysis on antisymmetric cracked FGM plates for simply supported boundary conditions has been investigated by Tran et al. [21] using a formulation that combines the eXtended IsoGeometric Approach (XIGA) and HSDT. IsoGeometric Analysis (IGA) utilizing the Non-Uniform Rational B-Spline (NURBS) functions is incorporated with enrichment functions through the partition of unity method in order to stimulate the cracked FGM plates. Using generalized differential quadrature (GDQ) method, Asadi and Fariborz [22] analysed the vibration of laminated composite plates with mixed boundary conditions. Another study on FGM plates has been carried out by Selim et al. [23]. In the study, element-free IMLS-Ritz method together with Reddy's

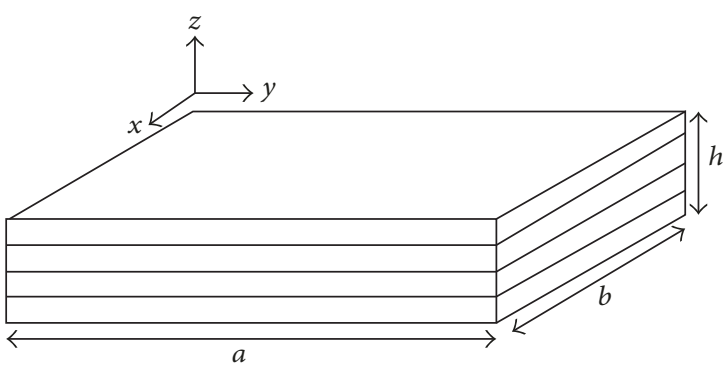

FIGURE 1: Geometry of the layered rectangular plate.

HSDT was implemented to the solution of FGM plates with piezoelectric layers.

Although plenty of studies on the vibration of plates using higher-order theory have been conducted, the free vibration analysis of antisymmetric angle-ply laminated plates with variable thickness using third-order shear deformation theory has not been investigated yet. In this paper, the laminated plates of linear, exponential, and sinusoidal thickness variation with simply supported boundary conditions are considered. Governing equations are derived from Hamilton's principle. Spline method is used to approximate the solution. Further, variations of frequency of laminated plates are discussed at various parameters such as aspect ratio, number of layers, ply-angles, side-to-thickness ratio, and materials. Numerical examples are presented to illustrate the accuracy and efficiency of the present theory in predicting the natural frequencies of laminates by comparing the present results with the results obtained in the literatures.

\section{Formulation}

Consider an antisymmetric angle-ply laminated rectangular plate in the Cartesian coordinates $x, y$, and $z$ where $z$ is taken as the normal to the plate and $h$ is the constant thickness as shown in Figure 1. According to third-order shear deformation theory (TSDT), the displacement field is assumed as [4]

$$
\begin{aligned}
u(x, y, z, t)= & u_{0}(x, y, t)+z \phi_{x}(x, y, t) \\
& -\frac{4 z^{3}}{3 h^{2}}\left(\phi_{x}+\frac{\partial w_{0}}{\partial x}\right) \\
v(x, y, z, t)= & v_{0}(x, y, t)+z \phi_{y}(x, y, t) \\
& -\frac{4 z^{3}}{3 h^{2}}\left(\phi_{y}+\frac{\partial w_{0}}{\partial y}\right) \\
w(x, y, z, t)= & w_{0}(x, y, t),
\end{aligned}
$$

where $u, v$, and $w$ are the displacement components in the $x$, $y$, and $z$ directions, respectively, $u_{0}$ and $v_{0}$ and $w_{0}$ are the inplane displacements of the middle plane, and $\phi_{x}$ and $\phi_{y}$ are the shear rotations of any point on the middle surface of the plate. 
In-plane strains are defined as

$$
\begin{aligned}
& \varepsilon=\left\{\begin{array}{c}
\varepsilon_{x} \\
\varepsilon_{y} \\
\gamma_{x y}
\end{array}\right\} \\
& \varepsilon=\varepsilon^{0}+z \varepsilon^{1}+z^{3} \varepsilon^{3},
\end{aligned}
$$

where

$$
\begin{aligned}
& \varepsilon^{0}=\left\{\begin{array}{c}
\varepsilon_{x}^{0} \\
\varepsilon_{y}^{0} \\
\gamma_{x y}^{0}
\end{array}\right\}=\left\{\begin{array}{c}
\frac{\partial u_{0}}{\partial x} \\
\frac{\partial v_{0}}{\partial y} \\
\frac{\partial u_{0}}{\partial y}+\frac{\partial v_{0}}{\partial x}
\end{array}\right\}, \\
& \varepsilon^{1}=\left\{\begin{array}{c}
\varepsilon_{x}^{1} \\
\varepsilon_{y}^{1} \\
\gamma_{x y}^{1}
\end{array}\right\}=\left\{\begin{array}{c}
\frac{\partial \phi_{x}}{\partial x} \\
\frac{\partial \phi_{y}}{\partial y} \\
\frac{\partial \phi_{x}}{\partial y}+\frac{\partial \phi_{y}}{\partial x}
\end{array}\right\} \\
& \varepsilon^{3}=\left\{\begin{array}{c}
\varepsilon_{x}^{3} \\
\varepsilon_{y}^{3} \\
\gamma_{x y}^{3}
\end{array}\right\}=\left(-\frac{4}{3 h^{2}}\right)\left\{\begin{array}{c}
\frac{\partial \phi_{x}}{\partial x}+\frac{\partial^{2} w_{0}}{\partial x^{2}} \\
\frac{\partial \phi_{y}}{\partial y}+\frac{\partial^{2} w_{0}}{\partial y^{2}} \\
\frac{\partial \phi_{x}}{\partial y}+\frac{\partial \phi_{y}}{\partial x}+2 \frac{\partial^{2} w_{0}}{\partial x \partial y}
\end{array}\right\},
\end{aligned}
$$

and the shear strain components are defined as

$$
\begin{aligned}
& \gamma=\left\{\begin{array}{l}
\gamma_{y z} \\
\gamma_{x z}
\end{array}\right\} \\
& \gamma=\gamma^{0}+z^{2} \gamma^{2},
\end{aligned}
$$

where

$$
\begin{aligned}
& \gamma^{0}=\left\{\begin{array}{l}
\gamma_{y z}^{0} \\
\gamma_{x z}^{0}
\end{array}\right\}=\left\{\begin{array}{l}
\phi_{y}+\frac{\partial w_{0}}{\partial y} \\
\phi_{x}+\frac{\partial w_{0}}{\partial x}
\end{array}\right\}, \\
& \gamma^{2}=\left\{\begin{array}{l}
\gamma_{y z}^{2} \\
\gamma_{x z}^{2}
\end{array}\right\}=\left(-\frac{4}{h^{2}}\right)\left\{\begin{array}{l}
\phi_{y}+\frac{\partial w_{0}}{\partial y} \\
\phi_{x}+\frac{\partial w_{0}}{\partial x}
\end{array}\right\} .
\end{aligned}
$$

The stress-strain relations for the $k$ th layer, after neglecting transverse normal strain and stress, are of the form

$$
\begin{aligned}
& \left(\begin{array}{c}
\sigma_{x}{ }^{(k)} \\
\sigma_{y}{ }^{(k)} \\
\tau_{x y}{ }^{(k)} \\
\tau_{y z}{ }^{(k)} \\
\tau_{x z}{ }^{(k)}
\end{array}\right) \\
& \left(\begin{array}{ccccc}
C_{11}{ }^{(k)} & C_{12}{ }^{(k)} & C_{16}{ }^{(k)} & 0 & 0 \\
C_{12}{ }^{(k)} & C_{22}{ }^{(k)} & C_{26}{ }^{(k)} & 0 & 0 \\
C_{16}{ }^{(k)} & C_{26}{ }^{(k)} & C_{66}{ }^{(k)} & 0 & 0 \\
0 & 0 & 0 & C_{44}{ }^{(k)} & C_{45}{ }^{(k)} \\
0 & 0 & 0 & C_{45}{ }^{(k)} & C_{55}{ }^{(k)}
\end{array}\right)\left(\begin{array}{c}
\varepsilon_{x}{ }^{(k)} \\
\varepsilon_{y}{ }^{(k)} \\
\gamma_{x y}{ }^{(k)} \\
\gamma_{y z}{ }^{(k)} \\
\gamma_{x z}{ }^{(k)}
\end{array}\right) .
\end{aligned}
$$

When the materials are oriented at an angle $\theta$ with the $x$-axis, the transformed stress-strain relations are

$$
\begin{aligned}
& \left(\begin{array}{c}
\sigma_{x}{ }^{(k)} \\
\sigma_{y}{ }^{(k)} \\
\tau_{x y}{ }^{(k)} \\
\tau_{y z}{ }^{(k)} \\
\tau_{x z}{ }^{(k)}
\end{array}\right) \\
& =\left(\begin{array}{ccccc}
Q_{11}{ }^{(k)} & Q_{12}{ }^{(k)} & Q_{16}{ }^{(k)} & 0 & 0 \\
Q_{12}{ }^{(k)} & Q_{22}{ }^{(k)} & Q_{26}{ }^{(k)} & 0 & 0 \\
Q_{16}{ }^{(k)} & Q_{26}{ }^{(k)} & Q_{66}{ }^{(k)} & 0 & 0 \\
0 & 0 & 0 & Q_{44}{ }^{(k)} & Q_{45}{ }^{(k)} \\
0 & 0 & 0 & Q_{45}{ }^{(k)} & Q_{55}{ }^{(k)}
\end{array}\right)\left(\begin{array}{c}
\varepsilon_{x}{ }^{(k)} \\
\varepsilon_{y}{ }^{(k)} \\
\gamma_{x y}{ }^{(k)} \\
\gamma_{y z}{ }^{(k)} \\
\gamma_{x z}{ }^{(k)}
\end{array}\right),
\end{aligned}
$$

where $Q_{i j}{ }^{(k)}$, as functions of $C_{i j}{ }^{(k)}$, are expressed as

$$
\begin{aligned}
Q_{11}^{(k)}= & C_{11}^{(k)} \cos ^{4} \theta+C_{22}^{(k)} \sin ^{4} \theta \\
& +2\left(C_{12}^{(k)}+2 C_{66}^{(k)}\right) \sin ^{2} \theta \cos ^{2} \theta \\
Q_{22}^{(k)}= & C_{11}^{(k)} \sin ^{4} \theta+C_{22}^{(k)} \cos ^{4} \theta \\
& +2\left(C_{12}^{(k)}+2 C_{66}^{(k)}\right) \sin ^{2} \theta \cos ^{2} \theta \\
Q_{12}^{(k)}= & \left(C_{11}^{(k)}+C_{22}^{(k)}-C_{66}^{(k)}\right) \sin ^{2} \theta \cos ^{2} \theta \\
& +C_{12}^{(k)}\left(\cos ^{4} \theta+\sin ^{4} \theta\right) \\
Q_{16}^{(k)}= & \left(C_{11}^{(k)}-C_{12}^{(k)}-2 C_{66}^{(k)}\right) \cos ^{3} \theta \sin ^{4} \theta \\
& -\left(C_{22}^{(k)}-C_{12}^{(k)}-2 C_{66}^{(k)}\right) \sin ^{3} \theta \cos ^{(k)}, \\
Q_{26}^{(k)}= & \left(C_{11}^{(k)}-C_{12}^{(k)}-2 C_{66}^{(k)}\right) \cos ^{3} \theta \sin ^{3} \theta \\
& -\left(C_{22}^{(k)}-C_{12}^{(k)}-2 C_{66}^{(k)}\right) \sin ^{3} \theta \cos ^{3} \theta
\end{aligned}
$$




$$
\begin{aligned}
Q_{66}^{(k)}= & \left(C_{11}^{(k)}+C_{22}^{(k)}-2 C_{12}^{(k)}-2 C_{66}^{(k)}\right) \cos ^{2} \theta \sin ^{2} \theta \\
& +C_{66}^{(k)}\left(\sin ^{4} \theta+\cos ^{4} \theta\right), \\
Q_{44}^{(k)}= & C_{55}^{(k)} \sin ^{2} \theta+C_{44}^{(k)} \cos ^{2} \theta, \\
Q_{55}^{(k)}= & C_{55}^{(k)} \cos ^{2} \theta+C_{44}^{(k)} \sin ^{2} \theta, \\
Q_{45}^{(k)}= & \left(C_{55}^{(k)}-C_{44}^{(k)}\right) \cos \theta \sin \theta,
\end{aligned}
$$

where

$$
\begin{aligned}
& C_{11}^{k}=\frac{E^{(k)}}{1-\nu_{12}^{(k)} v_{21}^{(k)}}, \\
& C_{12}^{k}=\frac{v_{12}^{(k)} E_{2}^{(k)}}{1-v_{12}^{(k)} \nu_{21}^{(k)}}=\frac{v_{21}^{(k)} E_{1}^{(k)}}{1-\nu_{12}^{(k)} v_{21}^{(k)}}, \\
& C_{11}^{k}=\frac{E_{2}^{(k)}}{1-v_{12}^{(k)} v_{21}^{(k)}}, \\
& C_{66}^{k}=G_{12}^{(k)}, \\
& C_{44}^{(k)}=G_{23}^{(k)}, \\
& C_{55}^{(k)}=G_{13}^{(k)} .
\end{aligned}
$$

The stress resultants are defined as

$$
\begin{aligned}
& \left\{\begin{array}{c}
N_{i} \\
M_{i} \\
P_{i}
\end{array}\right\}=\int_{-h / 2}^{h / 2} \sigma_{i}\left\{\begin{array}{c}
1 \\
z \\
z^{3}
\end{array}\right\} d z, \\
& \left\{\begin{array}{c}
Q_{i} \\
R_{i}
\end{array}\right\}=\int_{-h / 2}^{h / 2} \tau_{i}\left\{\begin{array}{c}
1 \\
z^{2}
\end{array}\right\} d z,
\end{aligned}
$$

where $N_{i}, M_{i}$, and $Q_{i}$ are stress, moment, and shear resultants, respectively. $P_{i}$ and $R_{i}$ denote higher-order stress resultants. The stress-strain relations are obtained as follows:

$$
\left(\begin{array}{c}
N \\
M \\
P \\
Q \\
R
\end{array}\right)=\left(\begin{array}{ccccc}
A & B & E & 0 & 0 \\
B & D & F & 0 & 0 \\
E & F & H & 0 & 0 \\
0 & 0 & 0 & A^{\prime} & D^{\prime} \\
0 & 0 & 0 & D^{\prime} & F^{\prime}
\end{array}\right)\left(\begin{array}{c}
\varepsilon^{0} \\
\varepsilon^{1} \\
\varepsilon^{3} \\
\gamma^{0} \\
\gamma^{2}
\end{array}\right) .
$$

Stiffness coefficients are defined as

$$
\begin{aligned}
A_{i j} & =A_{i j}^{c} g(r), \\
B_{i j} & =B_{i j}^{c} g(r), \\
D_{i j} & =D_{i j}^{c} g(r), \\
D_{i j} & =D_{i j}^{c} g(r) \\
E_{i j} & =E_{i j}^{c} g(r) \\
F_{i j} & =F_{i j}^{c} g(r) \\
H_{i j} & =H_{i j}^{c} g(r) \\
A_{i j}^{\prime} & =A_{i j}^{c} g(r) \\
D_{i j}^{\prime} & =D_{i j}^{c} g(r) \\
F_{i j}^{\prime} & =F_{i j}^{c} g(r) \\
A_{i j}^{c} & =\sum_{k} \bar{Q}_{i j}^{(k)}\left(z_{k}-z_{k-1}\right), \\
B_{i j}^{c} & =\frac{1}{2} \sum_{k} \bar{Q}_{i j}^{(k)}\left(z^{2}{ }_{k}-z^{2}{ }_{k-1}\right), \\
D_{i j}^{c} & =\frac{1}{3} \sum_{k} \bar{Q}_{i j}^{(k)}\left(z^{3}{ }_{k}-z^{3}{ }_{k-1}\right), \\
E_{i j}^{c} & =\frac{1}{4} \sum_{k} \bar{Q}_{i j}^{(k)}\left(z^{4}{ }_{k}-z^{4}{ }_{k-1}\right), \\
F_{i j}^{c} & =\frac{1}{5} \sum_{k} \bar{Q}_{i j}^{(k)}\left(z^{5}{ }_{k}-z^{5}{ }_{k-1}\right), \\
H_{i j}^{c} & =\frac{1}{7} \sum_{k} \bar{Q}_{i j}^{(k)}\left(z^{7}{ }_{k}-z^{7}{ }_{k-1}\right), \\
&
\end{aligned}
$$

for $i, j=1,2,6$,

$$
\begin{aligned}
& A_{i j}^{\prime c}=\sum_{k} \bar{Q}_{i j}^{(k)}\left(z_{k}-z_{k-1}\right), \\
& D_{i j}^{\prime c}=\frac{1}{3} \sum_{k} \bar{Q}_{i j}^{(k)}\left(z_{k}^{3}-z_{k-1}^{3}\right), \\
& F_{i j}^{c c}=\frac{1}{5} \sum_{k} \bar{Q}_{i j}^{(k)}\left(z_{k}^{5}-z_{k-1}^{5}\right),
\end{aligned}
$$

for $i, j=4,5$,

where the elastic coefficients $A_{i j}, B_{i j}$, and $D_{i j}$ (extensional, bending-extensional coupling, and bending stiffness) and $E_{i j}$, $F_{i j}$, and $H_{i j}$ are the higher-order stiffness coefficients. The boundaries of the $k$ th layer are represented by $z_{k-1}$ and $z_{k}$. The thickness of the $k$ th layer can be considered as

$$
h_{k}(x)=h_{0 k} g(x),
$$


where $g(x)=1+C_{\ell}(x / \ell)+C_{e} \exp (x / \ell)+C_{s} \sin (\pi x / \ell)$, in which $h_{k}$ and $h_{0 k}$ are the variable thickness and constant thickness of the $k$ th layer, respectively, and $C_{\ell}, C_{e}$, and $C_{s}$ are the coefficients of variable thickness. It should be noted that when $g(x)=1$, the thickness of the plate becomes constant.

The equilibrium equations considered are as follows:

$$
\begin{aligned}
& \frac{\partial N_{x}}{\partial x}+\frac{\partial N_{x y}}{\partial y}=I_{0} \frac{\partial^{2} u}{\partial t^{2}}, \\
& \frac{\partial N_{x y}}{\partial x}+\frac{\partial N_{y}}{\partial y}=I_{0} \frac{\partial^{2} v}{\partial t^{2}}, \\
& \frac{\partial \bar{Q}_{x}}{\partial x}+\frac{\partial \bar{Q}_{y}}{\partial y}+c_{1}\left(\frac{\partial^{2} P_{x}}{\partial x^{2}}+2 \frac{\partial^{2} P_{x y}}{\partial x \partial y}+\frac{\partial^{2} P_{y}}{\partial y^{2}}\right) \\
& =I_{0} \frac{\partial^{2} w}{\partial t^{2}}-c_{1}^{2} I_{6}\left(\frac{\partial^{4} w_{0}}{\partial x^{2} \partial t^{2}}+\frac{\partial^{4} w_{0}}{\partial y^{2} \partial t^{2}}\right) \\
& \quad+c_{1} J_{4}\left(\frac{\partial^{3} \phi_{x}}{\partial x \partial t^{2}}+\frac{\partial^{3} \phi_{y}}{\partial y \partial t^{2}}\right) \\
& \frac{\partial \bar{M}_{x x}}{\partial x}+\frac{\partial \bar{M}_{x y}}{\partial y}-\bar{Q}_{x}=K_{2} \frac{\partial^{2} \phi_{x}}{\partial t^{2}}-c_{1} J_{4} \frac{\partial^{3} w}{\partial x \partial t^{2}}, \\
& \frac{\partial \bar{M}_{x y}}{\partial x}+\frac{\partial \bar{M}_{y y}}{\partial y}-\bar{Q}_{y}=K_{2} \frac{\partial^{2} \phi_{y}}{\partial t^{2}}-c_{1} J_{4} \frac{\partial^{3} w}{\partial x \partial t^{2}},
\end{aligned}
$$

where $I_{i}$ are the normal and rotary inertia coefficients defined by

$$
I_{i}=\int_{z} \rho^{(k)}(z)^{i} d z \quad(i=0,1,2,3, \ldots, 6),
$$

where $\rho$ is the material density of the $k$ th layer and

$$
\begin{aligned}
\bar{M}_{\alpha \beta} & =M_{\alpha \beta}-c_{1} P_{\alpha \beta}, \\
\bar{Q}_{\alpha} & =Q_{\alpha}-c_{2} R_{\alpha}, \\
J_{4} & =I_{4}-c_{1} I_{6}, \\
K_{2} & =I_{2}-2 c_{1} I_{4}+c_{1}^{2} I_{6}, \\
c_{1} & =\frac{4}{3 h^{2}}, \\
c_{2} & =3 c_{1} .
\end{aligned}
$$

Substitute (2) and (4) in (11) and then substitute in (14). Further, equate the following laminate stiffness equal to zero for antisymmetric angle-ply laminates [14]:

$$
\begin{gathered}
A_{16}, A_{26}, A_{45}, B_{11}, B_{12}, B_{22}, B_{66}, D_{16}, D_{26}, D_{45}, E_{11}, E_{12}, \\
E_{22}, E_{66}, H_{16}, H_{26}, F_{16}, F_{26}, F_{45}=0 .
\end{gathered}
$$

The displacements and rotational functions are assumed in the separable form for antisymmetric angle-ply plates as

$$
\begin{aligned}
u(x, y) & =U(x) \cos \frac{n \pi y}{b} e^{i \omega t} \\
v(x, y) & =V(x) \sin \frac{n \pi y}{b} e^{i \omega t} \\
w(x, y) & =W(x) \sin \frac{n \pi y}{b} e^{i \omega t} \\
\phi_{x}(x, y) & =\Phi_{x}(x) \sin \frac{n \pi y}{b} e^{i \omega t} \\
\phi_{y}(x, y) & =\Phi_{y}(x) \cos \frac{n \pi y}{b} e^{i \omega t},
\end{aligned}
$$

where $\omega$ is the angular frequency of vibration and $t$ is the time and $n$ is the circumferential mode number. The nondimensional parameters introduced are as follows:

$\lambda=\omega a \sqrt{\frac{I_{0}}{A_{11}}}$, a frequency parameter

$\delta_{k}$

$=\frac{h_{k}}{h}$, the relative layer thickness of the $k$-th layer

$\phi=\frac{a}{b}$, aspect ratio

$X=\frac{x}{a}$, a distance co-ordinate

$H=\frac{a}{h}$, side-to-thickness ratio.

Using (18) and introducing nondimensional parameters, modified equations in the matrix form are obtained as

$$
\left[\begin{array}{l}
L_{11} L_{12} L_{13} L_{14} L_{15} \\
L_{21} L_{22} L_{23} L_{24} L_{25} \\
L_{31} L_{32} L_{33} L_{34} L_{35} \\
L_{41} L_{42} L_{43} L_{44} L_{45} \\
L_{51} L_{52} L_{53} L_{54} L_{55}
\end{array}\right]\left\{\begin{array}{c}
U \\
V \\
W \\
\Phi_{X} \\
\Phi_{Y}
\end{array}\right\}=\left\{\begin{array}{l}
0 \\
0 \\
0 \\
0 \\
0
\end{array}\right\},
$$

where $L_{i j}$ are shown in Appendix.

\section{Method of Solution}

The differential equations in (20) contain derivatives of second order in $U(X)$, third order in $V(X)$, fourth order in $W(X)$, third order in $\Phi_{X}(X)$, and second order in $\Phi_{Y}(X)$. These functions are approximated by using cubic and quantic spline functions, in the range of $X \varepsilon[0,1]$, since splines are relatively simple and elegant and use series of lower order approximations rather than global higher-order approximations, affording fast convergence and high accuracy. 
The displacement functions $U(X), V(X)$, and $W(X)$ and the rotational functions $\Phi_{X}(X)$ and $\Phi_{Y}(X)$ are approximated, respectively, by the splines

$$
\begin{gathered}
U(X)=\sum_{i=0}^{2} a_{i} X^{i}+\sum_{j=0}^{N-1} b_{j}\left(X-X_{j}\right)^{3} H\left(X-X_{j}\right), \\
V(X)=\sum_{i=0}^{4} c_{i} X^{i}+\sum_{j=0}^{N-1} d_{j}\left(X-X_{j}\right)^{5} H\left(X-X_{j}\right), \\
W(X)=\sum_{i=0}^{4} e_{i} X^{i}+\sum_{j=0}^{N-1} f_{j}\left(X-X_{j}\right)^{5} H\left(X-X_{j}\right), \\
\Phi_{X}(X)=\sum_{i=0}^{4} g_{i} X^{i}+\sum_{j=0}^{N-1} p_{j}\left(X-X_{j}\right)^{5} H\left(X-X_{j}\right), \\
\Phi_{Y}(X)=\sum_{i=0}^{2} l_{i} X^{i}+\sum_{j=0}^{N-1} q_{j}\left(X-X_{j}\right)^{3} H\left(X-X_{j}\right) .
\end{gathered}
$$

Here $H\left(X-X_{j}\right)$ is the Heaviside step function and $N$ is the number of intervals into which the range $[0,1]$ of $X$ is divided. The points $X=X_{s}=s / N(s=0,1,2, \ldots, N)$ are chosen as the knots of the splines, as well as the collocation points. Thus the splines are assumed to satisfy the differential equations given by (19), at all $X_{s}$. The resulting expressions contain $(5 N+5)$ homogeneous system of equations in the $(5 N+21)$ spline coefficients.

The boundary condition considered is (S-S): both the ends simply supported where $V=W=\Phi_{y}=N_{x}=$ $M_{x}=N_{x y}=P_{x}=\bar{M}_{x}=0$ at $X=0$ and $X=1$ [27]. This boundary condition gives 13 more equations, thus making a total of $(5 N+18)$ equations, in the same number of unknowns. The resulting field and boundary condition equations may be written in the form

$$
[M]\{q\}=\lambda^{2}[P]\{q\},
$$

where $[M]$ and $[P]$ are square matrixes and $\{q\}$ is a column vector. This is treated as a generalized eigenvalue problem in the eigenparameter $\lambda$ and the eigenvector $\{q\}$ whose elements are the spline coefficients.

\section{Results and Discussion}

4.1. Validation. In order to demonstrate the accuracy of the present analysis, some illustrative examples are solved and the numerical results are compared with data available in the literature. The comparison of fundamental frequencies of four-layered antisymmetric angle-ply plates for side-tothickness ratio fixed as 2 and 4 is tabulated in Table 1. The present results obtained for plate with S-S boundary conditions are compared with the results from Swaminathan and Patil [24] and Reddy [25]. The nondimensional frequency parameter $\Omega$ is defined as $\Omega=\left(\omega b^{2} / h\right) \sqrt{\rho / E_{2}}$. In Table 2, comparison study is presented for present results with FSDT results of Reddy [26] where he used FEM. The present parameter is converted into the nondimensional frequency
TABLE 1: Comparative study of fundamental frequencies, $\Omega=\left(\omega b^{2} / h\right) \sqrt{\rho / E_{2}}$, for simply supported four-layered $\left[45^{\circ} /-45^{\circ} / 45^{\circ} /-45^{\circ}\right]$ antisymmetric angle-ply laminated plate with $a / b=0.2$.

\begin{tabular}{lccc}
\hline $\begin{array}{l}\text { Lamination and } \\
\text { number of layers }\end{array}$ & Source & $a / h=2$ & $a / h=4$ \\
\hline & Present & 5.5012 & 10.0511 \\
{$\left[45^{\circ} /-45^{\circ} / 45^{\circ} /-45^{\circ}\right]$} & Ref. [24] & 5.5674 & 10.0731 \\
& Ref. [25] & 6.1067 & 10.6507 \\
\hline
\end{tabular}

TABle 2: Comparative study of fundamental frequencies, $\lambda=\omega a^{2}\left(\rho / E h^{2}\right)^{1 / 2}$, for simply supported four-layered $\left[30^{\circ} /-30^{\circ} / 30^{\circ} /-30^{\circ}\right]$ antisymmetric angle-ply laminated plate under FSDT with $a / b=0.2$.

\begin{tabular}{lcccccc}
\hline$a / h$ & 10 & 20 & 30 & 40 & 50 & 60 \\
\hline Present & 9.7420 & 11.748 & 12.335 & 12.579 & 12.734 & 13.021 \\
Ref. [26] & 11.106 & 12.595 & 12.972 & 13.136 & 13.233 & 13.301 \\
\hline
\end{tabular}

parameter given in Reddy [26], where $\lambda=\omega a^{2}\left(\rho / E h^{2}\right)^{1 / 2}$. The material properties used for both comparison in Tables 1 and 2 are $E_{1} / E_{2}=40, G_{12} / E_{2}=G_{13} / E_{2}=0.6, G_{23} / E_{2}=0.5$, and $v_{12}=v_{13}=v_{23}=0.25$. It can be observed from Tables 1 and 2 that the present results agree well with results of Swaminathan and Patil [24] and Reddy [25, 26].

4.2. Effects of Parameter on Laminated Plates. The structural parameters give influence on the vibration behaviour of laminated plates structures. In this subsection, the effects of aspect ratio, number of layers, ply-angles, side-to-thickness ratio, variable thickness, and materials are investigated. Two materials are considered, Kevlar-49/epoxy (KE) and Graphite/Epoxy (AS4/3501-6) (GE), and the material properties are shown in Table 3. Also, two- and four-layered plates with antisymmetric angle-ply orientations are considered.

Table 4 shows the frequency parameters of four-layered laminated plate with respect to taper ratio $\eta$ for $0.5 \leq \eta \leq$ 2.1. The following data for the laminated plate are used: $a / b=1$ and $a / h=10$. The materials are oriented in the form of $\mathrm{GE} / \mathrm{KE} / \mathrm{KE} / \mathrm{GE}$ with ply-angle $\left[45^{\circ} /-45^{\circ} / 45^{\circ} /-45^{\circ}\right]$ for S-S boundary conditions. From the table, it is shown that the frequency parameter shows inconsistency since the value slightly increased and decreased over the variation of taper ratio, $0.5 \leq \eta \leq 2.1$. It also can be seen that the frequency parameter is higher for higher mode. The effects of coefficient of exponential and sinusoidal thickness variation on the frequency parameter for antisymmetric angle-ply laminated plates with S-S boundary conditions are shown in Tables 5 and 6 , respectively, using the same parameters as fixed in Table 4. The value of $C_{e}$ ranges for $-0.2 \leq \eta \leq 0.2$ while $C_{s}$ varies for $-0.5 \leq \eta \leq 0.5$. From both tables, it is seen that the value of frequency parameter does not give significant difference throughout the range of $C_{e}$ and $C_{s}$ for every mode.

Figures 2(a), 2(b), and 2(c) depict the variation of frequency parameter of antisymmetric angle-ply laminated plate with respect to side-to-thickness ratio, $a / h$, for different aspect ratios $a / b=0.4, a / b=1$, and $a / b=1.6$, 
TABLE 3: Material properties of the plates.

\begin{tabular}{|c|c|c|c|c|c|c|c|}
\hline Material & $\begin{array}{c}\text { Density } \\
\rho \times 10^{3}-s^{2} / m^{4}\end{array}$ & $\begin{array}{l}\text { Young's Modulus } \\
E_{x} \times 10^{10} \mathrm{~N} / \mathrm{m}^{2}\end{array}$ & $\begin{array}{c}\text { Young's } \\
\text { Modulus } \\
E_{\theta} \times 10^{10} \mathrm{~N} / \mathrm{m}^{2}\end{array}$ & $\begin{array}{l}\text { Shear Modulus } \\
G_{x \theta} \times 10^{10} \mathrm{~N} / \mathrm{m}^{2}\end{array}$ & $\begin{array}{l}\text { Shear Modulus } \\
G_{\theta z} \times 10^{10} \mathrm{~N} / \mathrm{m}^{2}\end{array}$ & $\begin{array}{l}\text { Shear Modulus } \\
G_{x z} \times 10^{10} \mathrm{~N} / \mathrm{m}^{2}\end{array}$ & $\begin{array}{c}\text { Poisson Ratio } \\
v_{x \theta}\end{array}$ \\
\hline $\mathrm{KE}$ & 1440 & 86.19 & 5.52 & 2.07 & 2.07 & 1.72 & 0.34 \\
\hline GE & 1770 & 9.65 & 144.80 & 4.14 & 4.14 & 3.45 & 0.30 \\
\hline
\end{tabular}

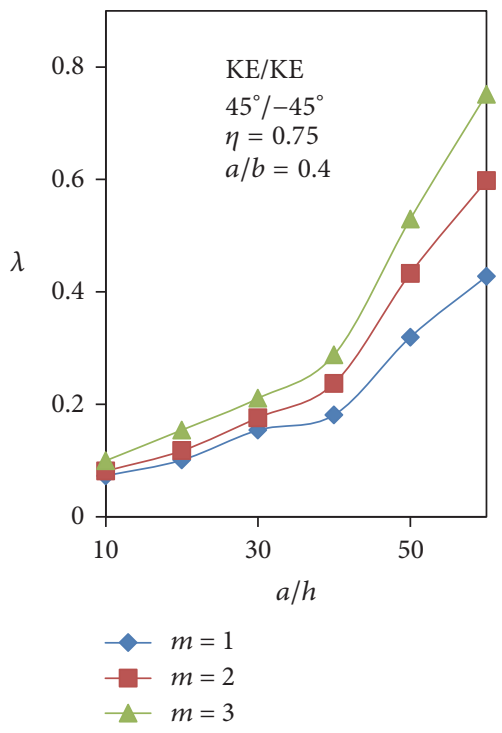

(a)

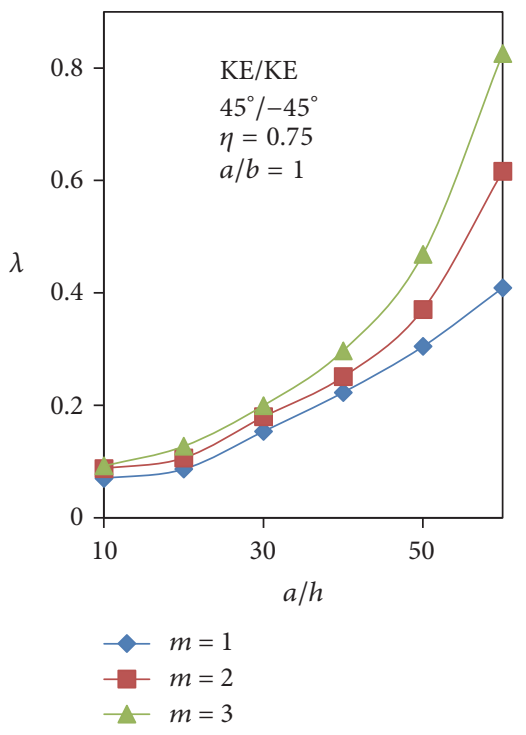

(b)

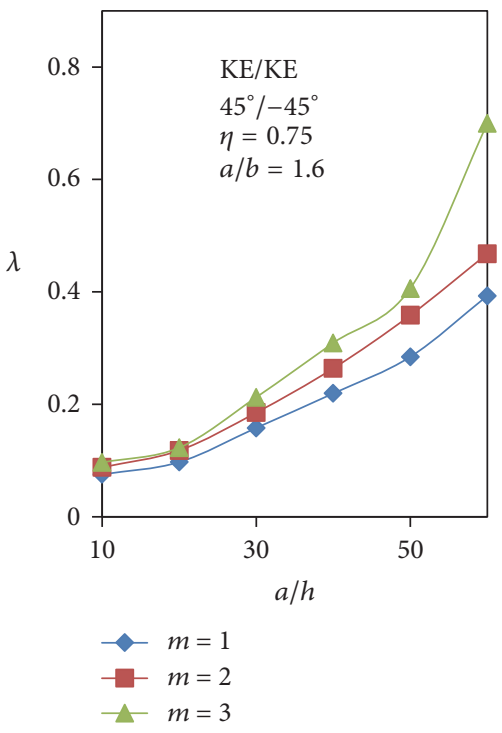

(c)

FIGURE 2: Effect of frequency parameter of two-layered antisymmetric angle-ply plates with respect to side-to-thickness ratio consisting of linear thickness variation.

TABLE 4: Frequency parameter values $\lambda_{m}(m=1,2,3)$ of a plate with respect to the variation of taper ratio $\eta$.

\begin{tabular}{lccc}
\hline$\eta$ & $\lambda_{1}$ & $\lambda_{2}$ & $\lambda_{3}$ \\
\hline 0.5 & 0.16398 & 0.17338 & 0.18789 \\
0.7 & 0.16374 & 0.17589 & 0.18609 \\
0.9 & 0.16362 & 0.17468 & 0.19048 \\
1.1 & 0.16368 & 0.17227 & 0.19291 \\
1.3 & 0.16409 & 0.17327 & 0.19561 \\
1.5 & 0.16401 & 0.17479 & 0.19561 \\
1.7 & 0.16370 & 0.17472 & 0.19614 \\
1.9 & 0.16337 & 0.17768 & 0.19614 \\
2.1 & 0.16342 & 0.17667 & 0.1999 \\
\hline
\end{tabular}

respectively. The results are presented for linearly varying thickness plate. The parameters considered are $\eta=0.75$ with material KE oriented in the form of $\left[45^{\circ} /-45^{\circ}\right]$. It is observed that, for all cases, as the side-to-thickness ratio increases, the values of frequency parameter increase. Also it is observed that the maximum frequency is obtained for $a / b=1$ and $a / h=60$ in Figure 2(b). From Figure 2 we can see that aspect ratio can considerably change the frequency parameter of laminated plates. The influence of side-tothickness ratio on the vibration behaviour of antisymmetric
TABLE 5: Values of frequency parameter $\lambda_{m}(m=1,2,3)$ of a plate with respect to the coefficient of exponential thickness variation.

\begin{tabular}{lccc}
\hline$C_{e}$ & $\lambda_{1}$ & $\lambda_{2}$ & $\lambda_{3}$ \\
\hline-0.2 & 0.16363 & 0.17088 & 0.18932 \\
-0.1 & 0.16362 & 0.17145 & 0.19144 \\
0 & 0.16372 & 0.16944 & 0.18759 \\
0.1 & 0.16367 & 0.16876 & 0.18408 \\
0.2 & 0.16363 & 0.1687 & 0.18173 \\
\hline
\end{tabular}

TABLE 6: Values of frequency parameter $\lambda_{m}(m=1,2,3)$ of a plate with respect to the coefficient of sinusoidal thickness variation.

\begin{tabular}{lccc}
\hline$C_{s}$ & $\lambda_{1}$ & $\lambda_{2}$ & $\lambda_{3}$ \\
\hline-0.5 & 0.16447 & 0.17199 & 0.18086 \\
-0.3 & 0.16281 & 0.17347 & 0.18300 \\
-0.1 & 0.16379 & 0.17454 & 0.18216 \\
0.1 & 0.16361 & 0.17150 & 0.19156 \\
0.3 & 0.16378 & 0.17333 & 0.19568 \\
0.5 & 0.16364 & 0.17858 & 0.19793 \\
\hline
\end{tabular}

angle-ply laminated plate with exponentially and sinusoidally varying thickness is shown in Figures 3 and 4, respectively. The results are prepared for different value of aspect ratio, 


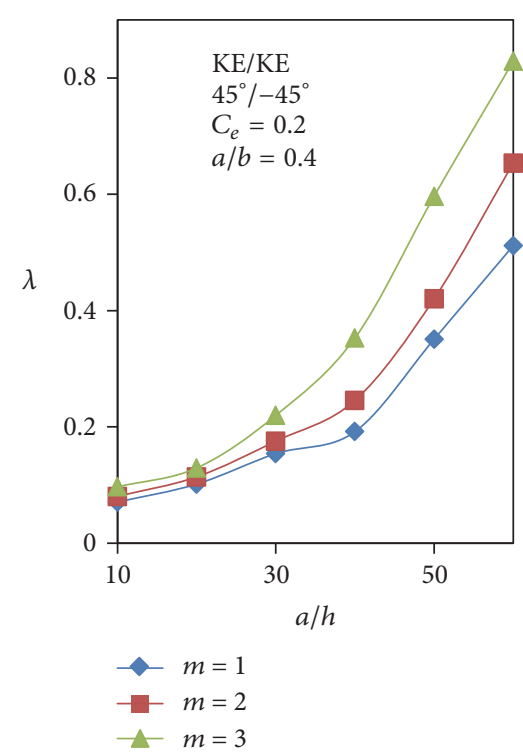

(a)

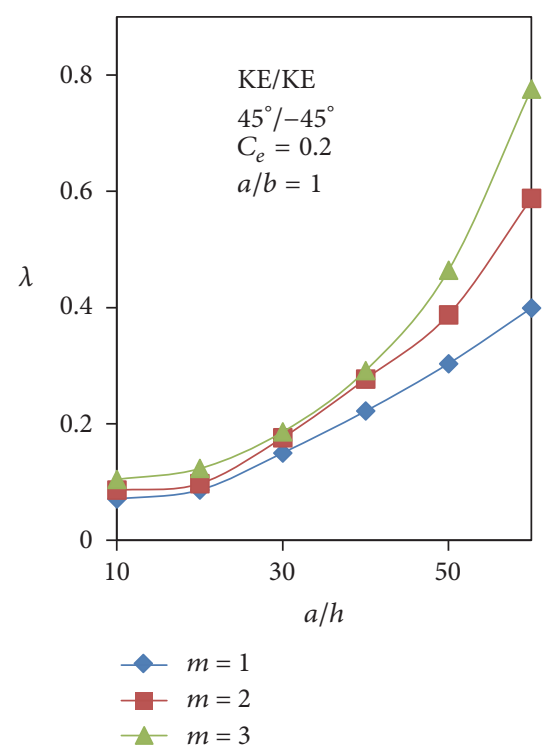

(b)

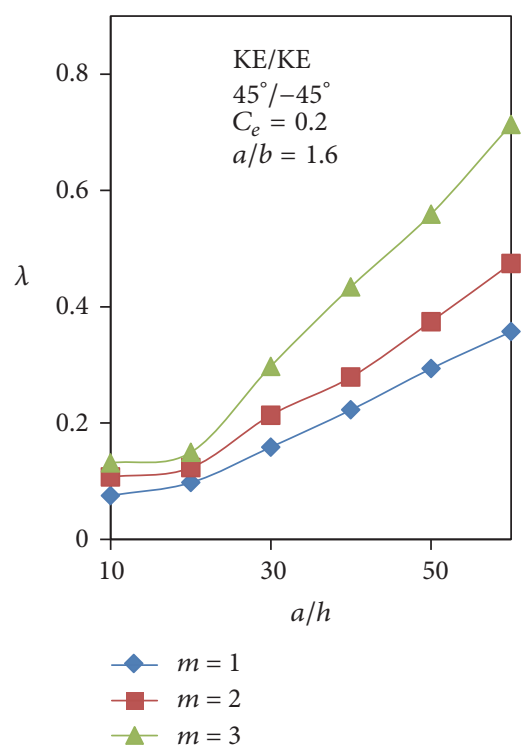

(c)

FIGURE 3: Effect of frequency variation of two-layered antisymmetric angle-ply plates with respect to side-to-thickness ratio consisting of exponential thickness variation.

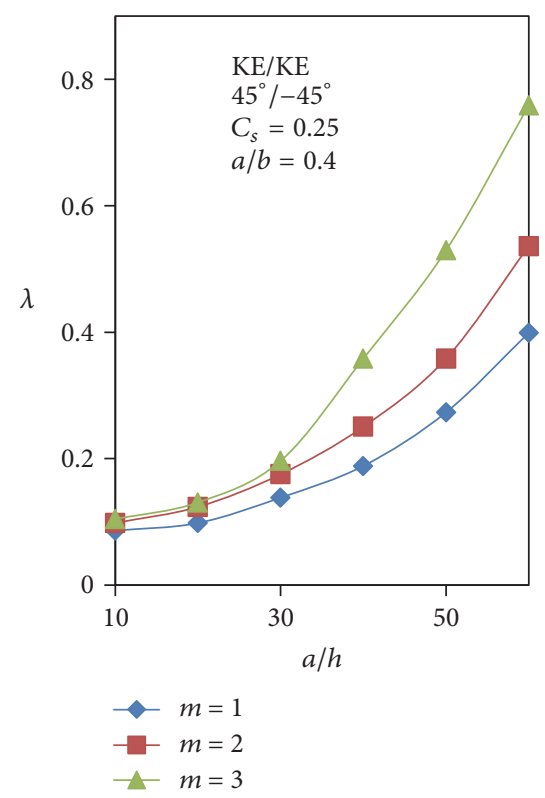

(a)

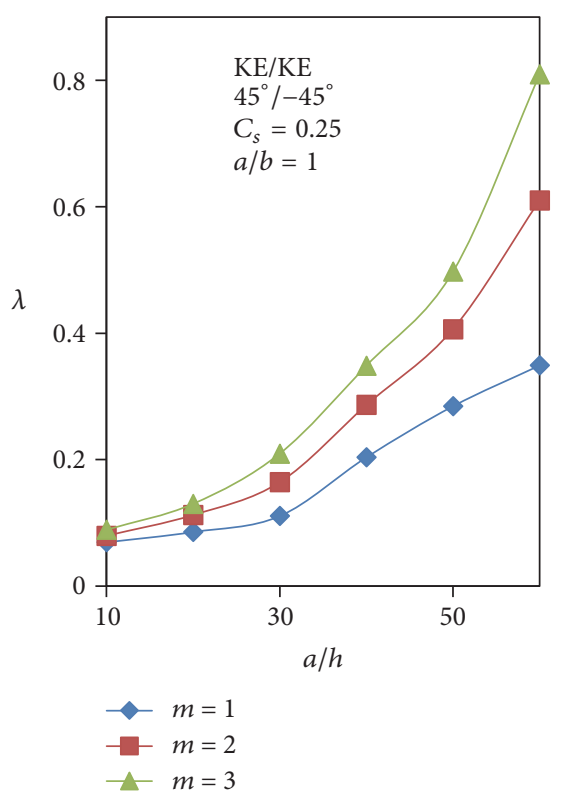

(b)

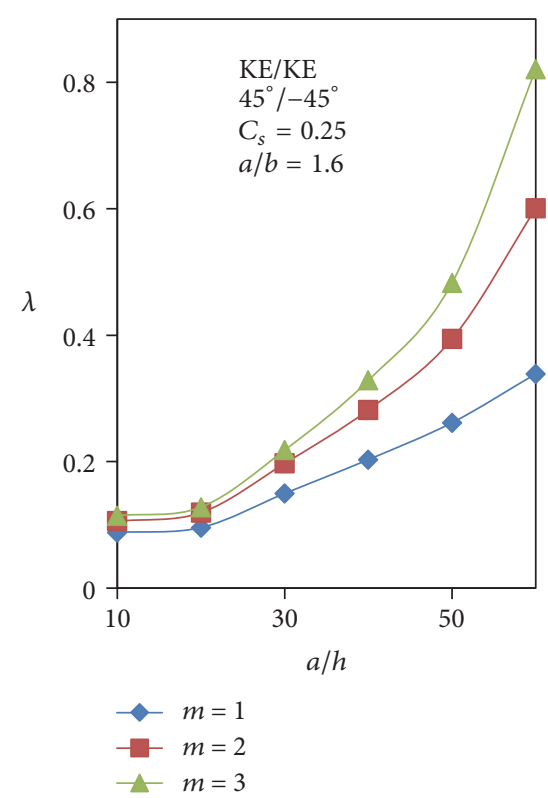

(c)

FIGURE 4: Effect of frequency variation of two-layered antisymmetric angle-ply plates with respect to side-to-thickness ratio consisting of sinusoidal thickness variation.

$a / b$. From both figures, we can see that the frequency values increase as $a / h$ increases. It is apparent that there is significant difference between responses of laminated plates under linear, exponential, and sinusoidal thickness variation from Figures 2, 3, and 4.

Figures 5(a), 5(b), and 5(c) show the effect of aspect ratio, $a / b$, on the frequency parameter of four-layered antisymmetric angle-ply laminated plates with linearly, exponentially, and sinusoidally varying thickness, respectively. The sideto-thickness ratio is fixed as $a / h=10$ and the orientation of laminated plates is $\left[45^{\circ} /-45^{\circ} / 45^{\circ} / 45^{\circ}\right]$ with material $\mathrm{GE} / \mathrm{KE} / \mathrm{KE} / \mathrm{GE}$. From the figure, the frequency parameters are seen to fluctuate over the range of aspect ratio $0.2 \leq$ $a / b \leq 2.2$. For all cases, the increase of $a / b$ from 0.2 to a certain point yields an increase of the frequency parameter and then the frequency drops to a certain point and once 


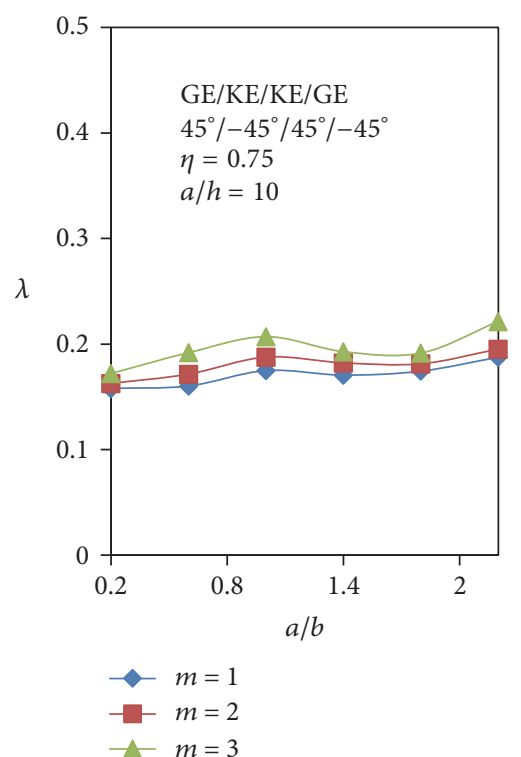

(a)

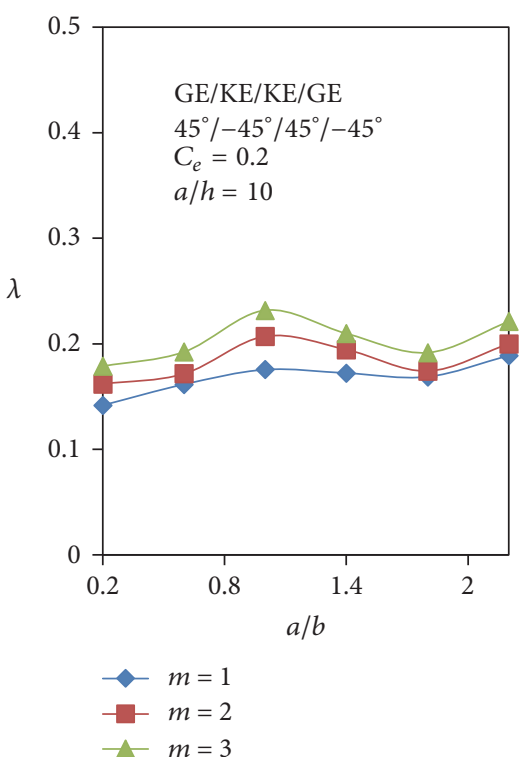

(b)

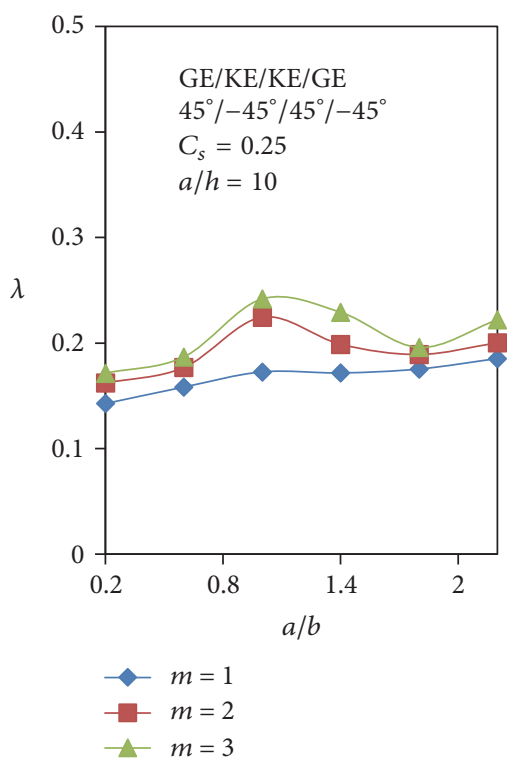

(c)

FIGURE 5: Variation of frequency parameter for four-layered antisymmetric angle-ply $\left(45^{\circ} /-45^{\circ} / 45^{\circ} /-45^{\circ}\right)$ plates with respect to aspect ratio. (a) $\eta=0.75$; (b) $C_{e}=0.2$; (c) $C_{s}=0.25$.

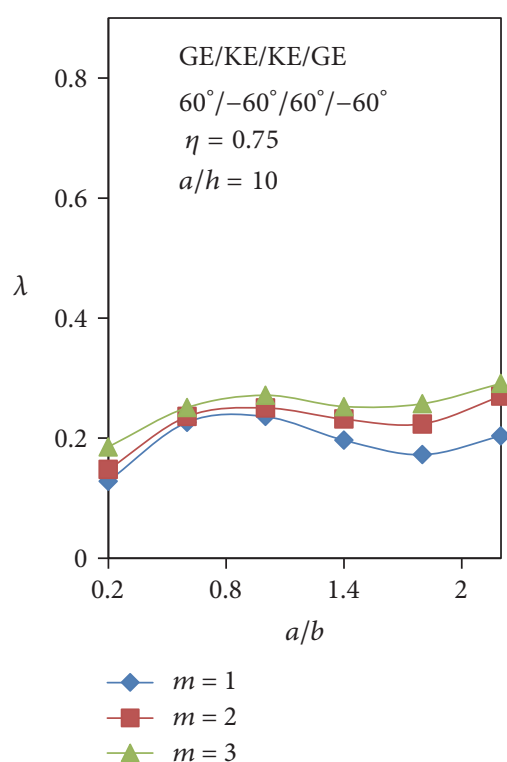

(a)

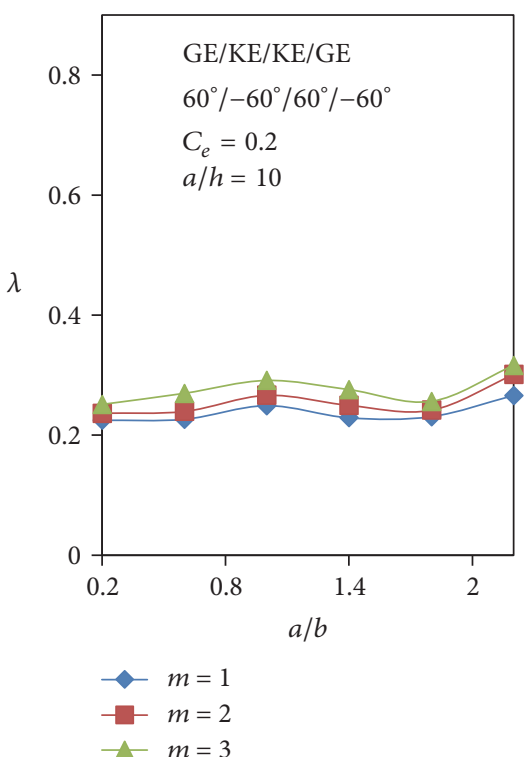

(b)

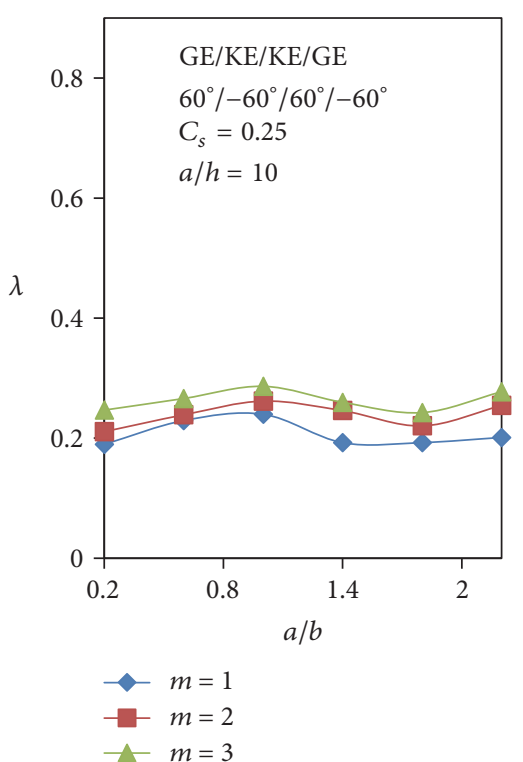

(c)

FIGURE 6: Variation of frequency parameter for four-layered antisymmetric angle-ply $\left[60^{\circ} /-60^{\circ} / 60^{\circ} /-60^{\circ}\right]$ plates with respect to aspect ratio. (a) $\eta=0.75$; (b) $C_{e}=0.2$; (c) $C_{s}=0.25$.

again increases afterwards. Another study on the variation of frequency parameter against aspect ratio with angle-ply $\left[60^{\circ} /-60^{\circ} / 60^{\circ} /-60^{\circ}\right]$ is carried out and presented in Figure 6. It is observed that the frequency parameter in Figure 6 has the same trend of variations as in Figure 5. However it can be seen that angle-ply gives influence on the frequency parameter of laminated plates.

Figures 7 and 8 depict the effects of ply-angle, $\theta$, on the frequency parameter of four- and two-layered laminated plates, respectively. All the three types of variation in thickness of layers are considered: $\eta=0.75, C_{e}=0.2$, and $C_{s}=0.25$. The parameters are fixed as $a / h=10$ and $a / b=1 ; \mathrm{GE}$ and $\mathrm{KE}$ are used which are arranged in the order of $\mathrm{KE} / \mathrm{GE} / \mathrm{GE} / \mathrm{KE}$ for four-layered plate and GE/GE for two-layered plate. It is seen that all the frequency parameter values increase gradually as $\theta$ increases. Also, it is can be seen that the frequency values are higher for four-layered plate compared to two-layered plate. Mode shapes for vibration 


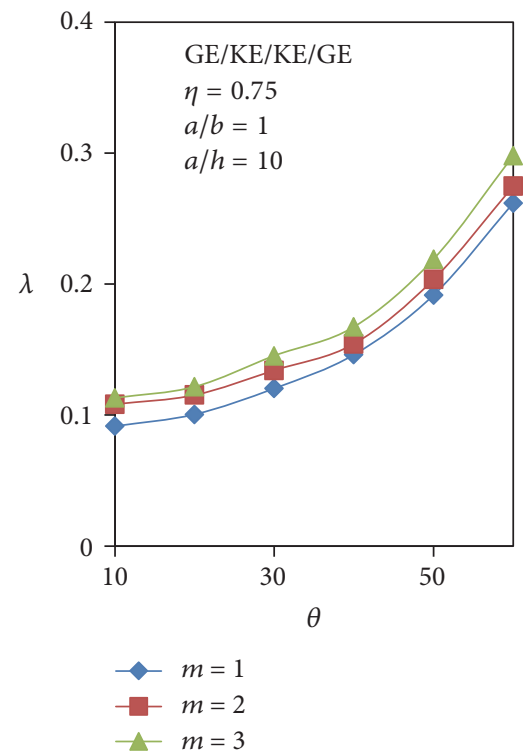

(a)

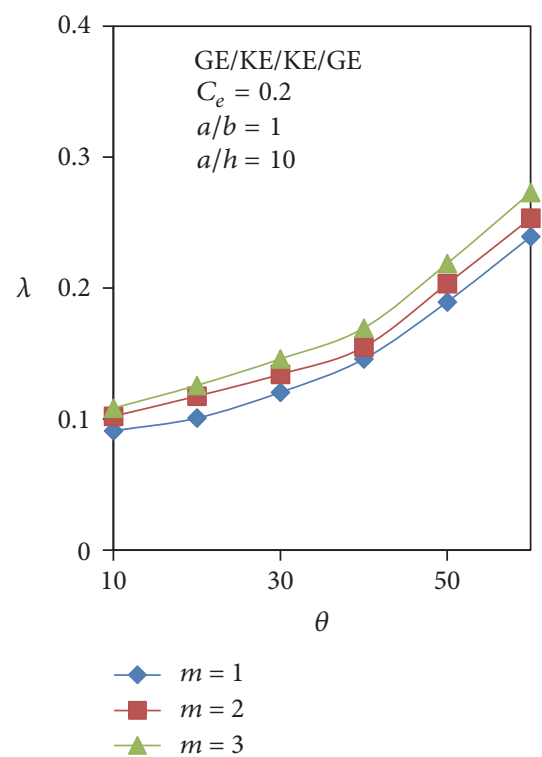

(b)

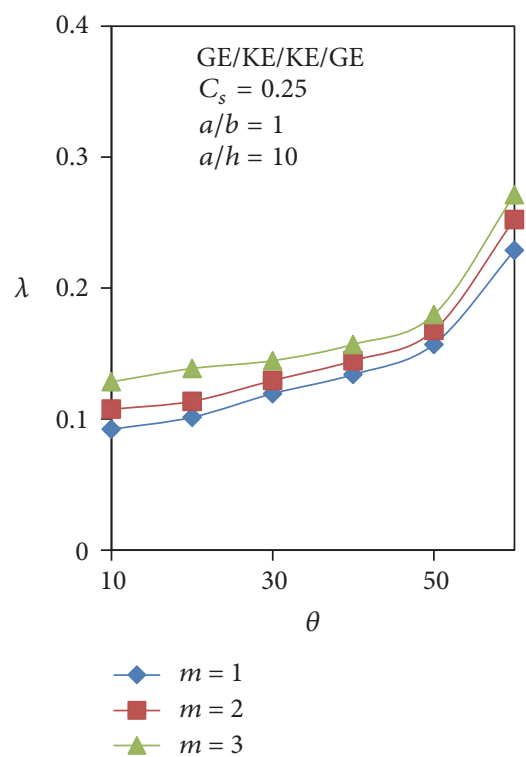

(c)

FIGURE 7: Variation of frequency parameter for four-layered antisymmetric angle-ply plates with respect to laying angle. (a) $\eta=0.75$; (b) $C_{e}=0.2 ;(\mathrm{c}) C_{s}=0.25$.

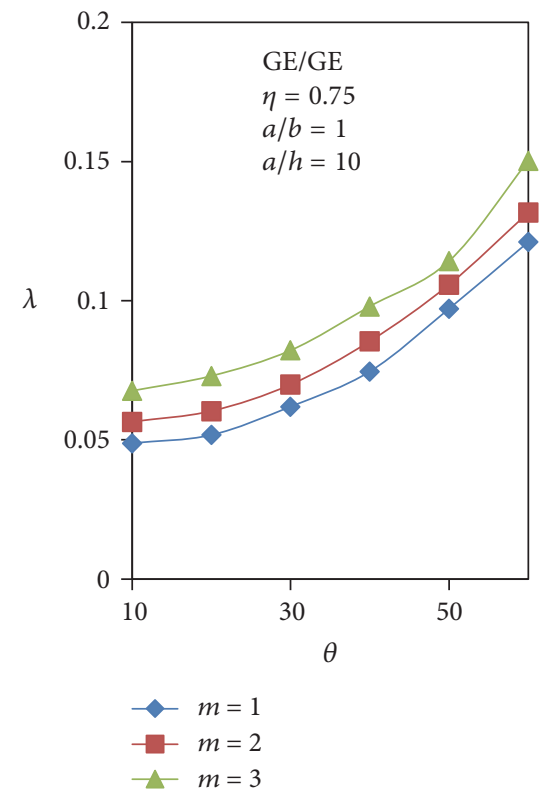

(a)

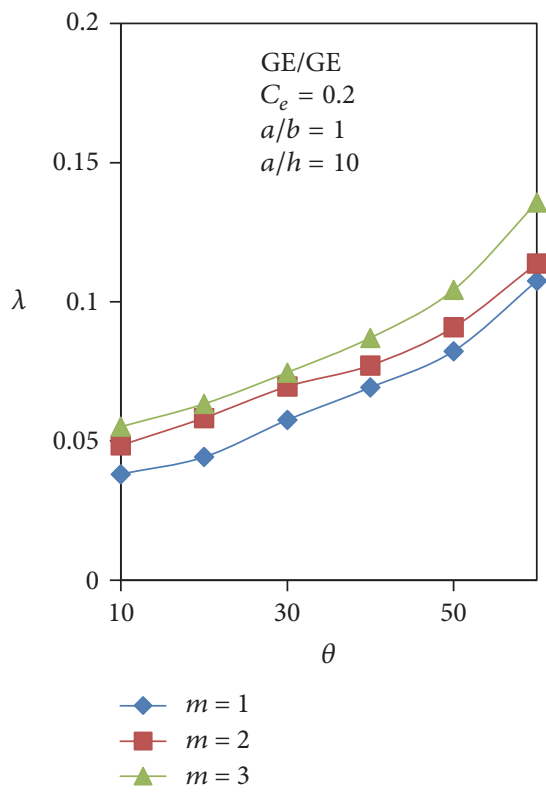

(b)

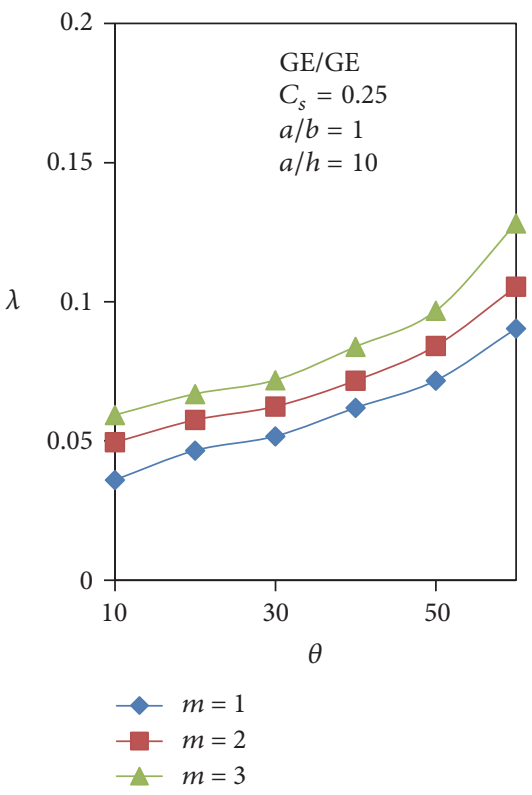

(c)

FIGURE 8: Variation of frequency parameter for two-layered antisymmetric angle-ply plates with respect to laying angle. (a) $\eta=0.75$; (b) $C_{e}=0.2$; (c) $C_{s}=0.25$.

of rectangular plate of linearly variable thickness for S-S boundary conditions up to the third mode are depicted in Figure 9. Displacements $U, V, W, \Phi_{x}$, and $\Phi_{y}$ are normalized with respect to the maximum transverse displacement $W$.

\section{Conclusion}

In this work, free vibration of antisymmetric angle-ply laminated plate under S-S boundary conditions for variable thickness is investigated. Spline method is used to approximate the solution into a set of algebraic equations which is then solved using eigensolution technique. Aspect ratio, side-to-thickness ratio, laying angle, number of lamina, and different lamination materials are seen to affect the frequency of the plate. A desired frequency of vibration may be obtained by a proper choice of those parameters. The nature of variation in thickness of layers considerably affects the natural frequencies. 


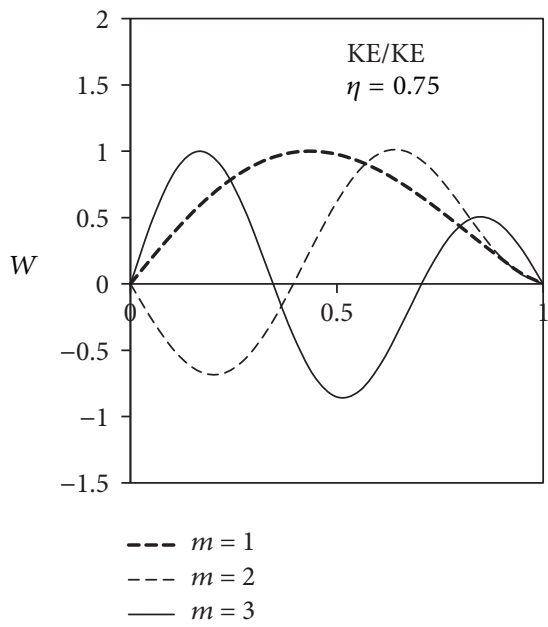

(a)

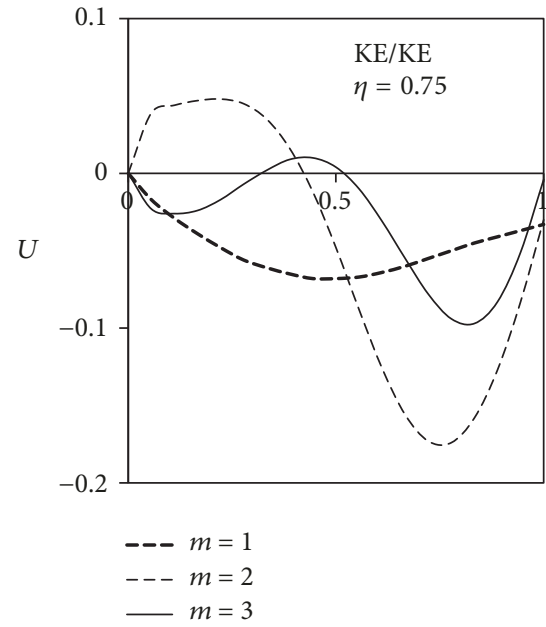

(b)

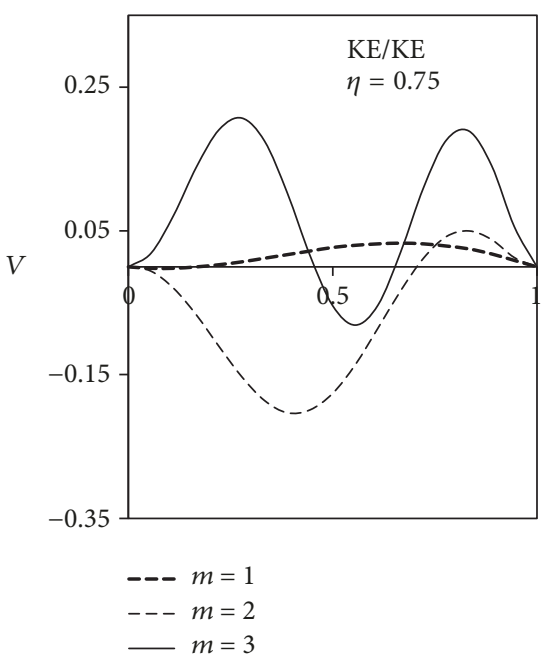

(c)

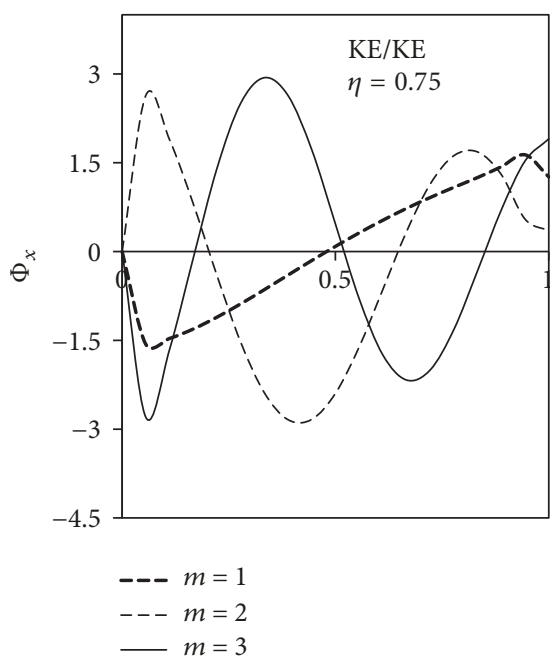

(d)

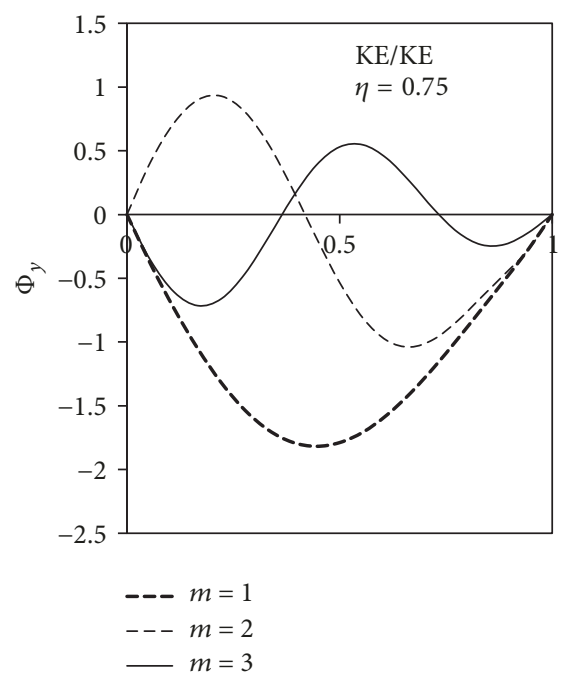

(e)

FIGURE 9: Mode shapes of rectangular plates for S-S boundary conditions.

\section{Appendix}

$$
\begin{aligned}
L_{11} & =\frac{d^{2}}{d X^{2}}+\frac{g^{\prime}}{g} \frac{d}{d X}-s_{10} \beta^{2}+\lambda^{2} \\
L_{12} & =\left(s_{2}+s_{10}\right) \beta \frac{d}{d X}+s_{2} \frac{g^{\prime}}{g} \\
L_{13} & =-3 s_{33} c_{1} \beta \frac{d^{2}}{d X^{2}}-2 s_{33} c_{1} \beta \frac{g^{\prime}}{g} \frac{d}{d X}+s_{34} c_{1} \beta^{3} \\
L_{14} & =2\left(s_{15}-s_{33} c_{1}\right) \beta \frac{d}{d X}+\left(s_{15}-s_{33} c_{1}\right) \beta \frac{g^{\prime}}{g} \\
L_{15} & =\left(s_{15}-s_{33} c_{1}\right) \frac{d^{2}}{d X^{2}}+\left(s_{15}-s_{33} c_{1}\right) \frac{g^{\prime}}{g} \frac{d}{d X}-\left(s_{16}\right. \\
& \left.-s_{34} c_{1}\right) \beta^{2}
\end{aligned}
$$

$$
\begin{aligned}
L_{21} & =-\left(s_{10}+s_{2}\right) \beta \frac{d}{d X}-s_{10} \beta \frac{g^{\prime}}{g} \\
L_{22} & =s_{10} \frac{d^{2}}{d X^{2}}+s_{10} \frac{g^{\prime}}{g} \frac{d}{d X}-s_{3} \beta^{2}+\lambda^{2} \\
L_{23} & =-s_{33} c_{1} \frac{d^{3}}{d X^{3}}-s_{33} c_{1} \frac{d^{2}}{d X^{2}}+3 s_{34} c_{1} \beta^{2} \frac{d}{d X} \\
& +s_{34} c_{1} \beta^{2} \frac{g^{\prime}}{g} \\
L_{24} & =\left(s_{15}-s_{33} c_{1}\right) \frac{d^{2}}{d X^{2}}+\left(s_{15}-s_{33} c_{1}\right) \frac{g^{\prime}}{g} \frac{d}{d X}-\left(s_{16}\right. \\
& \left.-s_{34} c_{1}\right) \beta^{2} \\
L_{25} & =-2\left(s_{16}-s_{34} c_{1}\right) \beta \frac{d}{d X}-\left(s_{16}-s_{34} c_{1}\right) \beta \frac{g^{\prime}}{g}
\end{aligned}
$$




$$
\begin{aligned}
& L_{31}=-3 s_{33} c_{1} \beta \frac{d^{2}}{d X^{2}}-4 s_{33} c_{1} \beta \frac{g^{\prime}}{g} \frac{d}{d X}-\left(s_{33} c_{1} \beta \frac{g^{\prime \prime}}{g}\right. \\
& \left.-s_{34} c_{1} \beta^{3}\right) \\
& L_{32}=s_{33} c_{1} \frac{d^{3}}{d X^{3}}+2 s_{33} c_{1} \frac{g^{\prime}}{g} \frac{d^{2}}{d X^{2}}+\left(s_{33} c_{1} \frac{g^{\prime \prime}}{g}\right. \\
& \left.-3_{34} c_{1} \beta^{2}\right) \frac{d}{d X}-3 s_{34} c_{1} \beta^{2} \\
& L_{33}=-s_{23} c_{1}^{2} \frac{d^{4}}{d X^{4}}-2 s_{23} c_{1}^{2} \frac{g^{\prime}}{g} \frac{d^{3}}{d X^{3}}+\left(2 s_{24} c_{1}^{2} \beta^{2}\right. \\
& +4 s_{28} c_{1}^{2} \beta^{2}+s_{14}-2 s_{30} c_{2}+s_{32} c_{2}^{2} \\
& \left.-s_{23} c_{1}^{2} \frac{g^{\prime \prime}}{g}\right) \frac{d^{2}}{d X^{2}}+\left(s_{14}-2 s_{30} c_{2}+s_{32} c_{2}^{2}\right. \\
& \left.+2 s_{24} c_{1}^{2} \beta^{2}+4 s_{28} c_{1}^{2} \beta^{2}\right) \frac{g^{\prime}}{g}-\left(s_{25} c_{1}^{2} \beta^{4}+s_{13} \beta^{2}\right. \\
& \left.-2 s_{29} c_{2} \beta^{2}+s_{31} c_{2}^{2} \beta^{2}-s_{24} c_{1}^{2} \beta^{2} \frac{g^{\prime \prime}}{g}\right) \\
& -c_{1}^{2} \lambda^{2} p_{3} \frac{d^{2}}{d X^{2}}+\left(\lambda^{2}+c_{1}^{2} \lambda^{2} p_{3} \beta^{2}\right) \\
& L_{34}=\left(s_{20} c_{1}-s_{23} c_{1}^{2}\right) \frac{d^{3}}{d X^{3}}+\left(s_{20} c_{1}-s_{23} c_{1}^{2}\right) \frac{g^{\prime}}{g} \frac{d^{2}}{d X^{2}} \\
& -\left(2 s_{27} c_{1} \beta^{2}-2 s_{28} c_{1}^{2} \beta^{2}+s_{21} c_{1} \beta^{2}-s_{24} c_{1}^{2} \beta^{2}-s_{14}\right. \\
& \left.+2 s_{30} c_{2}-s_{32} c_{2}^{2}-s_{20} c_{1} \frac{g^{\prime \prime}}{g}+s_{23} c_{1}^{2} \frac{g^{\prime \prime}}{g}\right) \frac{d}{d X} \\
& +\left(c_{1} \lambda^{2} p_{2}-c_{1}^{2} \lambda^{2} p_{3}\right) \frac{d}{d X}+\left(s_{14}+2 s_{30} c_{2}\right. \\
& \left.+s_{32} c_{2}^{2}-2 s_{27} c_{1} \beta^{2}+2 s_{28} c_{1}^{2} \beta^{2}\right) \\
& L_{35}=-\left(s_{21} c_{1}-s_{24} c_{1}^{2}+2 s_{27} c_{1}-2 s_{28} c_{1}^{2}\right) \beta \frac{d^{2}}{d X^{2}} \\
& -\left(2 s_{21} c_{1}-2 s_{24} c_{1}^{2}+2 s_{27} c_{1}-2 s_{28} c_{1}^{2}\right) \beta \frac{g^{\prime}}{g} \frac{d}{d X} \\
& +\left(s_{22} c_{1} \beta^{3}-s_{25} c_{1}^{2} \beta^{3}-s_{13} \beta+2 s_{29} \mathcal{c}_{2} \beta-s_{31} c_{2}^{2} \beta\right. \\
& \left.-s_{21} c_{1} \beta \frac{g^{\prime \prime}}{g}+s_{24} c_{1}^{2} \beta \frac{g^{\prime \prime}}{g}\right)-\left(c_{1} \lambda^{2} p_{2} \beta\right. \\
& \left.-c_{1}^{2} \lambda^{2} p_{3} \beta\right) \\
& L_{41}=-2\left(s_{15}-s_{33} c_{1}\right) \beta \frac{d}{d X}-\left(s_{15}-s_{33} c_{1}\right) \beta \frac{g^{\prime}}{g} \\
& \begin{aligned}
L_{42} & =\left(s_{15}-s_{33} c_{1}\right) \frac{d^{2}}{d X^{2}}+\left(s_{15}-s_{33} c_{1}\right) \frac{g^{\prime}}{g} \frac{d}{d X}-\left(s_{16}\right. \\
& \left.-s_{34} c_{1}\right) \beta^{2} \\
L_{43} & =\left(s_{23} c_{1}^{2}-s_{20} c_{1}\right) \frac{d^{3}}{d X^{3}}+\left(s_{23} c_{1}^{2}-s_{20} c_{1}\right) \frac{g^{\prime}}{g} \frac{d^{2}}{d X^{2}} \\
& -\left(s_{24} c_{1}^{2} \beta^{2}-s_{21} c_{1} \beta^{2}+2 s_{28} c_{1}^{2} \beta^{2}-2 s_{27} c_{1} \beta^{2}+s_{14}\right. \\
& \left.-2 s_{30} c_{2}+s_{32} c_{2}^{2}\right) \frac{d}{d X}-\left(c_{1} \lambda^{2} p_{2}\right. \\
& \left.-c_{1}^{2} \lambda^{2} p_{3}\right) \frac{d}{d X}-\left(s_{24} c_{1}^{2} \beta^{2}-s_{21} c_{1} \beta^{2}\right) \frac{g^{\prime}}{g} \\
L_{44} & =\left(s_{7}-2 s_{20} c_{1}+s_{23} c_{1}^{2}\right) \frac{d^{2}}{d X^{2}}-\left(s_{7}-2 s_{20} c_{1}\right. \\
& \left.+s_{23} c_{1}^{2}\right) \frac{g^{\prime}}{g} \frac{d}{d X}-\left(s_{12} \beta^{2}-2 s_{27} c_{1} \beta^{2}+s_{28} c_{1}^{2} \beta^{2}\right. \\
& \left.+s_{14}-2 s_{30} c_{2}+s_{32} c_{2}^{2}\right)+\left(\lambda^{2} p_{1}-2 c_{1} \lambda^{2} p_{2}\right. \\
& \left.+c_{1}^{2} \lambda^{2} p_{3}\right) \\
L_{45} & =-\left(s_{8}-2 s_{21} c_{1}+s_{24} c_{1}^{2}+s_{21}-2 s_{27} c_{1}+s_{28} c_{1}^{2}\right) \\
& +\beta \frac{d}{d X}-\left(s_{8}-2 s_{21} c_{1}+s_{24} c_{1}^{2}\right) \beta \frac{g^{\prime}}{g} \\
L_{51} & =\left(s_{15}-s_{33} c_{1}\right) \frac{d^{2}}{d X^{2}}+\left(s_{15}-s_{33} c_{1}\right) \frac{g^{\prime}}{g} \frac{d}{d X}-\left(s_{16}\right. \\
&
\end{aligned} \\
& L_{52}=2\left(s_{16}-s_{34} c_{1}\right) \beta \frac{d}{d X}+\left(s_{16}-s_{34} c_{1}\right) \beta \frac{g^{\prime}}{g} \\
& L_{53}=\left(2 s_{28} c_{1}^{2}-2 s_{27} c_{1}+s_{24} c_{1}^{2}-s_{21} c_{1}\right) \beta \frac{d^{2}}{d X^{2}} \\
& -\left(2 s_{27} c_{1}-2 s_{28} c_{1}^{2}\right) \beta \frac{g^{\prime}}{g} \frac{d}{d X}-\left(s_{25} c_{1}^{2} \beta^{3}-s_{22} c_{1} \beta^{3}\right. \\
& \left.+s_{13} \beta-2 s_{29} c_{2} \beta+s_{31} c_{2}^{2} \beta\right) \\
& L_{54}=\left(s_{12}-2 s_{27} c_{1}+s_{28} c_{1}^{2}+s_{8}-2 s_{21} c_{1}+s_{24} c_{1}^{2}\right) \\
& \cdot \beta \frac{d}{d X}+\left(s_{12}-2 s_{27} c_{1}+s_{28} c_{1}^{2}\right) \beta \frac{g^{\prime}}{g} \\
& L_{55}=\left(s_{12}-2 s_{27} c_{1}+s_{28} c_{1}^{2}\right) \frac{d^{2}}{d X^{2}}+\left(s_{12}-2 s_{27} c_{1}\right. \\
& \left.+s_{28} c_{1}^{2}\right) \frac{g^{\prime}}{g} \frac{d}{d X}-\left(s_{9} \beta^{2}-2 s_{22} c_{1} \beta^{2}+s_{25} c_{1}^{2} \beta^{2}+s_{13}\right. \\
& \left.-2 s_{29} c_{2}+s_{31} c_{2}^{2}\right)+\left(\lambda^{2} p_{1}-2 c_{1} \lambda^{2} p_{2}+c_{1}^{2} \lambda^{2} p_{3}\right) .
\end{aligned}
$$


The quantities $S_{i}(i=2, \ldots, 38)$ are defined by

$$
\begin{aligned}
& S_{2}=\frac{A_{12}}{A_{11}}, \\
& S_{3}=\frac{A_{22}}{A_{11}}, \\
& S_{4}=\frac{B_{11}}{a A_{11}}, \\
& S_{5}=\frac{B_{12}}{a A_{11}} \text {, } \\
& S_{6}=\frac{B_{22}}{a A_{11}} \text {, } \\
& S_{7}=\frac{D_{11}}{a^{2} A_{11}}, \\
& S_{8}=\frac{D_{12}}{a^{2} A_{11}}, \\
& S_{9}=\frac{D_{22}}{a^{2} A_{11}}, \\
& S_{10}=\frac{A_{66}}{A_{11}} \text {, } \\
& S_{11}=\frac{B_{66}}{a A_{11}}, \\
& S_{12}=\frac{D_{66}}{a^{2} A_{11}} \text {, } \\
& S_{13}=\frac{A_{44}}{A_{11}} \text {, } \\
& S_{14}=\frac{A_{55}}{A_{11}} \text {, } \\
& S_{15}=\frac{B_{16}}{a A_{11}} \\
& S_{16}=\frac{B_{26}}{a A_{11}} \text {, } \\
& S_{17}=\frac{E_{11}}{a^{3} A_{11}} \text {, } \\
& S_{18}=\frac{E_{12}}{a^{3} A_{11}} \text {, } \\
& S_{19}=\frac{E_{22}}{a^{3} A_{11}} \text {, } \\
& S_{20}=\frac{F_{11}}{a^{4} A_{11}} \text {, } \\
& S_{21}=\frac{F_{12}}{a^{4} A_{11}} \text {, } \\
& S_{22}=\frac{F_{22}}{a^{4} A_{11}}
\end{aligned}
$$$$
S_{23}=\frac{H_{11}}{a^{6} A_{11}},
$$$$
S_{24}=\frac{H_{12}}{a^{6} A_{11}} \text {, }
$$$$
S_{25}=\frac{H_{22}}{a^{6} A_{11}} \text {, }
$$$$
S_{26}=\frac{E_{66}}{a^{3} A_{11}} \text {, }
$$$$
S_{27}=\frac{F_{66}}{a^{4} A_{11}} \text {, }
$$$$
S_{28}=\frac{H_{66}}{a^{5} A_{11}} \text {, }
$$$$
S_{29}=\frac{D_{44}}{a^{2} A_{11}}
$$$$
S_{30}=\frac{D_{55}}{a^{2} A_{11}} \text {, }
$$$$
S_{31}=\frac{F_{44}}{a^{4} A_{11}},
$$$$
S_{32}=\frac{F_{55}}{a^{4} A_{11}},
$$$$
S_{33}=\frac{E_{16}}{a^{3} A_{11}},
$$$$
S_{34}=\frac{E_{26}}{a^{3} A_{11}},
$$$$
S_{35}=\frac{F_{16}}{a^{4} A_{11}},
$$$$
S_{36}=\frac{F_{26}}{a^{4} A_{11}}
$$$$
S_{37}=\frac{H_{16}}{a^{6} A_{11}},
$$$$
S_{38}=\frac{H_{26}}{a^{6} A_{11}} \text {. }
$$

\section{Conflicts of Interest}

The authors declare that there are no conflicts of interest regarding the publication of this paper.

\section{Acknowledgments}

This research was supported by the KIAT (Korea Institute for Advancement of Technology) grant funded by the Korea Government (MOTIE: Ministry of Trade Industry and Energy) (no. 0002361). 


\section{References}

[1] A. E. H. Love, "On the small free vibrations and deformations of a thin elastic shell," Philosophical Transactions of the Royal Society of London, vol. 179, pp. 491-546, 1888.

[2] E. Reissner, "Stress strain relations in the theory of thin elastic shells," Journal of Mathematical Physics, vol. 31, pp. 109-119, 1952.

[3] R. D. Mindlin, "Influence of rotary inertia and shear on flexural motions of isotropic, elastic plates," Journal of Applied Mechanics, vol. 18, pp. 31-38, 1951.

[4] J. N. Reddy, Theory and analysis of elastic plates and shells, CRC Press, New York, NY, USA, 2007.

[5] J. N. Reddy and C. F. Liu, "A higher-order shear deformation theory of laminated elastic shells," International Journal of Engineering Science, vol. 23, no. 3, pp. 319-330, 1985.

[6] A. Shahrjerdi and F. Mustapha, Second order shear deformation theory (SSDT) for free vibration analysis on a functionally graded quadrangle plate, vol. 4, Intech, 2011.

[7] S. Xiaoping and S. Liangxin, "An improved simple higher-order theory for laminated composite plates," Computers \& Structures, vol. 50, no. 2, pp. 231-236, 1994.

[8] B. Adim, T. H. Daouadji, and A. Rabahi, "A simple higher order shear deformation theory for mechanical behavior of laminated composite plates," International Journal of Advanced Structural Engineering, vol. 8, no. 2, pp. 103-117, 2016.

[9] J. S. Kumar, T. D. Raju, and K. V. Reddy, "Vibration analysis of composite laminated plates using higher-order shear deformation theory with zig-zag function," Indian Journal of Science and Technology, vol. 4, no. 8, pp. 960-966, 2011.

[10] N. F. Hanna and A. W. Leissa, "A higher order shear deformation theory for the vibration of thick plates," Journal of Sound and Vibration, vol. 170, no. 4, pp. 545-555, 1994.

[11] H. Zuo, Z.-B. Yang, X.-F. Chen, Y. Xie, and H. Miao, "Analysis of laminated composite plates using wavelet finite element method and higher-order plate theory," Composite Structures, vol. 131, pp. 248-258, 2015.

[12] Mallikarjuna and T. Kant, "Dynamics of laminated composite plates with a higher order theory and finite element discretization," Journal of Sound and Vibration, vol. 126, no. 3, pp. 463475, 1988.

[13] Mallikarjuna and T. Kant, "A higher-order theory for free vibration of unsymmetrically laminated composite and sandwich plates-finite element evaluations," Computers \& Structures, vol. 32, no. 5, pp. 1125-1132, 1989.

[14] L. W. Zhang and B. A. Selim, "Vibration analysis of CNTreinforced thick laminated composite plates based on Reddy's higher-order shear deformation theory," Composite Structures, vol. 160, pp. 689-705, 2017.

[15] J. Saira, K. K. Viswanathan, Z. A. Aziz, K. Karthik, and J. H. Lee, "Vibration of antisymmetric angle-ply laminated plates under higher order shear theory," Steel and Composite Structures, vol. 22, no. 6, pp. 1281-1299, 2016.

[16] M. Bouazza, Y. Kenouza, N. Benseddiq, and A. M. Zenkour, "A two-variable simplified nth-higher-order theory for free vibration behavior of laminated plates," Composite Structures, vol. 182, pp. 533-541, 2017.

[17] D. B. Singh and B. N. Singh, "New higher order shear deformation theories for free vibration and buckling analysis of laminated and braided composite plates," International Journal of Mechanical Sciences, vol. 131-132, pp. 265-277, 2017.
[18] H. A. Zamani, M. M. Aghdam, and M. Sadighi, "Free vibration analysis of thick viscoelastic composite plates on viscoPasternak foundation using higher-order theory," Composite Structures, vol. 182, pp. 25-35, 2017.

[19] H.-T. Thai and S.-E. Kim, "A simple higher-order shear deformation theory for bending and free vibration analysis of functionally graded plates," Composite Structures, vol. 96, pp. 165-173, 2013.

[20] T. I. Thinh, T. M. Tu, T. H. Quoc, and N. Van Long, "Vibration and buckling analysis of functionally graded plates using new eight-unknown higher order shear deformation theory," Latin American Journal of Solids and Structures, vol. 13, no. 3, pp. 456477,2016

[21] L. V. Tran, H. A. Ly, J. Lee, M. A. Wahab, and H. NguyenXuan, "Vibration analysis of cracked FGM plates using higherorder shear deformation theory and extended isogeometric approach," International Journal of Mechanical Sciences, vol. 9697, article no. 2944, pp. 65-78, 2015.

[22] E. Asadi and S. J. Fariborz, "Free vibration of composite plates with mixed boundary conditions based on higher-order shear deformation theory," Archive of Applied Mechanics, vol. 82, no. 6, pp. 755-766, 2012.

[23] B. A. Selim, L. W. Zhang, and K. M. Liew, "Active vibration control of FGM plates with piezoelectric layers based on Reddy's higher-order shear deformation theory," Composite Structures, vol. 155, pp. 118-134, 2016.

[24] K. Swaminathan and S. S. Patil, "Analytical solutions using a higher order refined computational model with 12 degrees of freedom for the free vibration analysis of antisymmetric angleply plates," Composite Structures, vol. 82, no. 2, pp. 209-216, 2008.

[25] J. N. Reddy, "A simple higher order theory for laminated composite plates," Journal of Applied Mechanics, vol. 51, no. 4, pp. 745-752, 1984.

[26] J. N. Reddy, "Free vibration of antisymmetric, angle-ply laminated plates including transverse shear deformation by the finite element method," Journal of Sound and Vibration, vol. 66, no. 4, pp. 565-576, 1979.

[27] J. N. Reddy, Mechanics of laminated composite plates, theory and analysis, CRC Press, Boca Raton, FL, USA, 1996. 


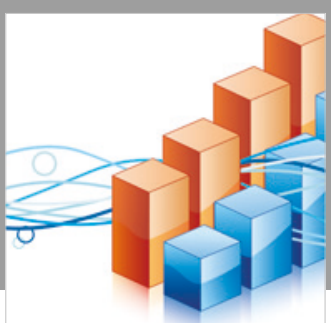

Advances in

Operations Research

\section{-n-m}
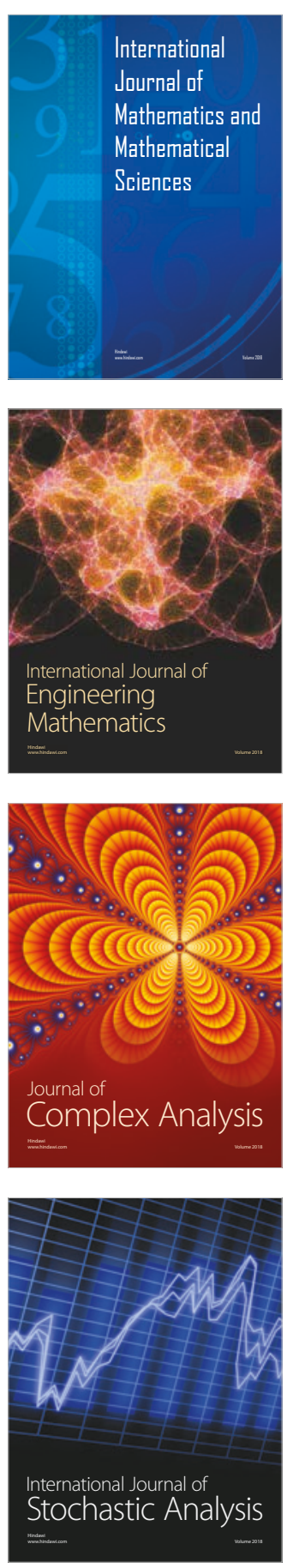
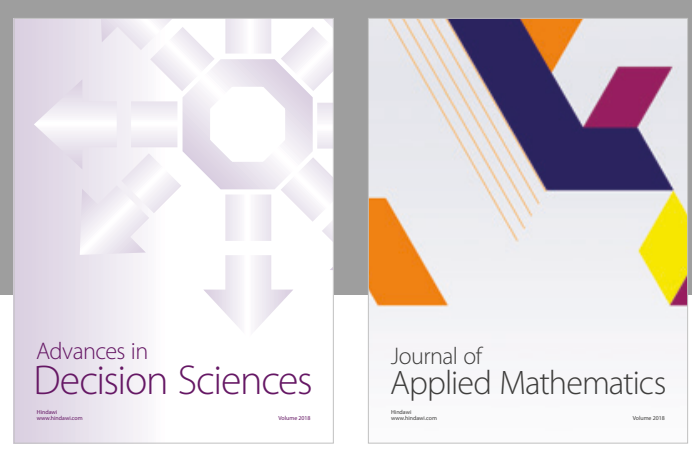

Journal of

Applied Mathematics
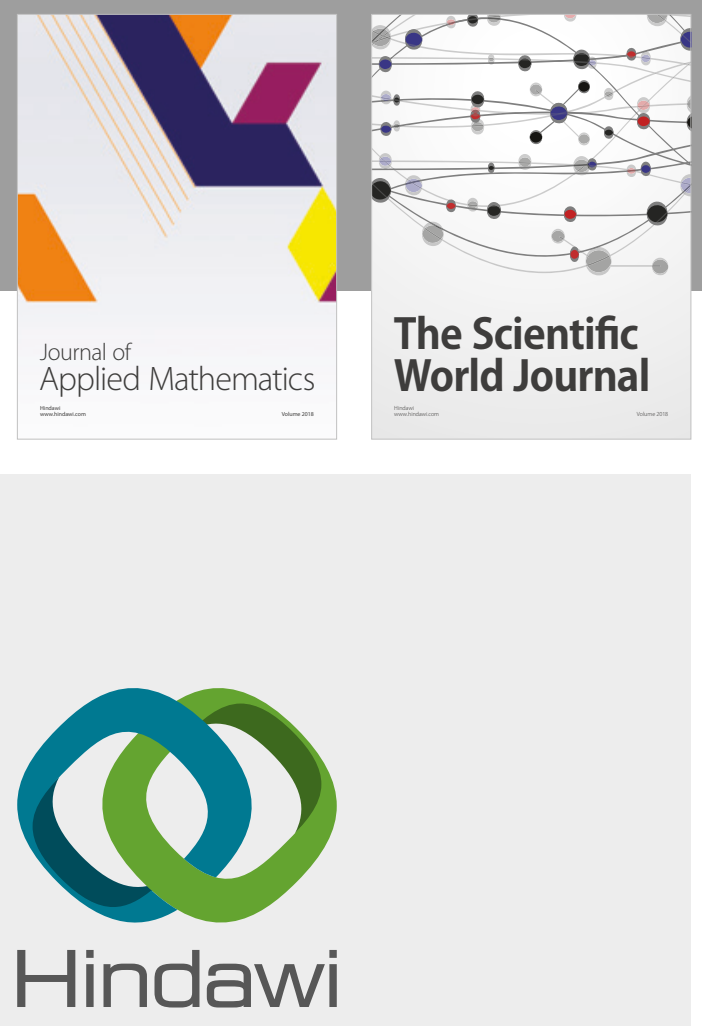

Submit your manuscripts at

www.hindawi.com

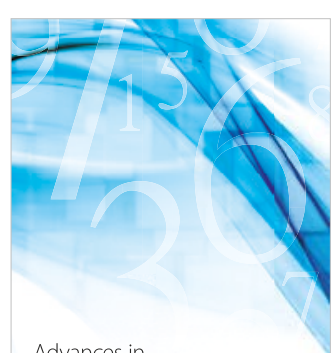

Advances in
Numerical Analysis
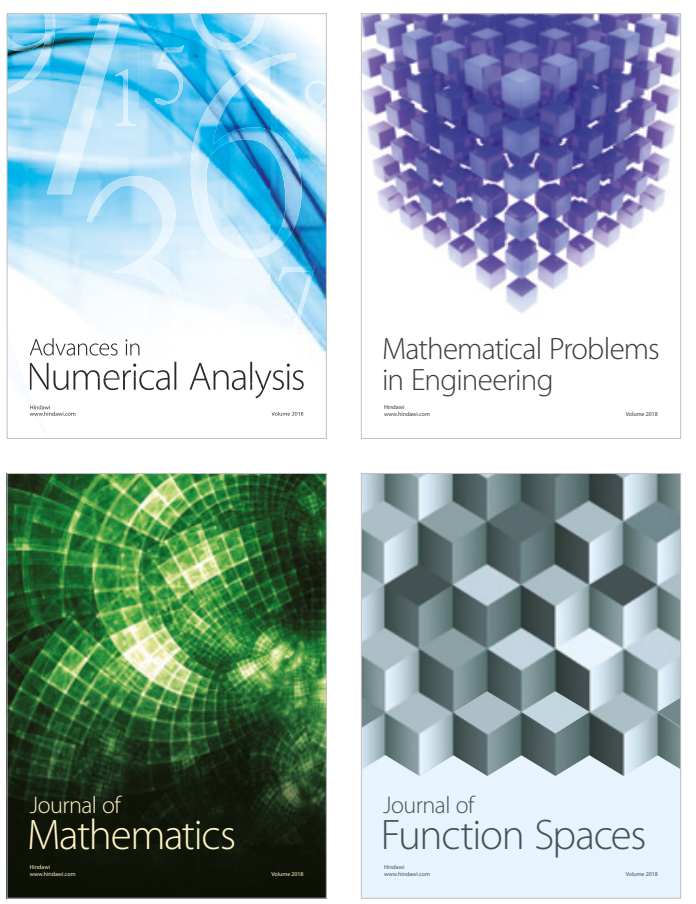

Mathematical Problems in Engineering

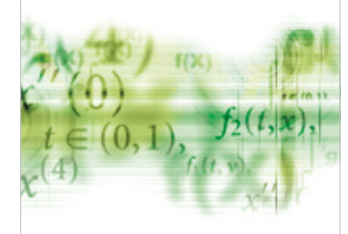

International Journal of

Differential Equations

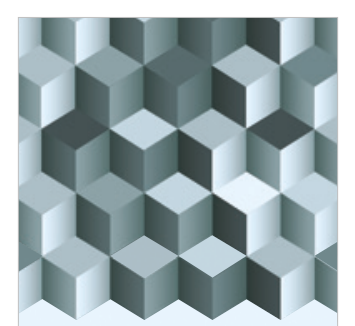

Journal of

Function Spaces

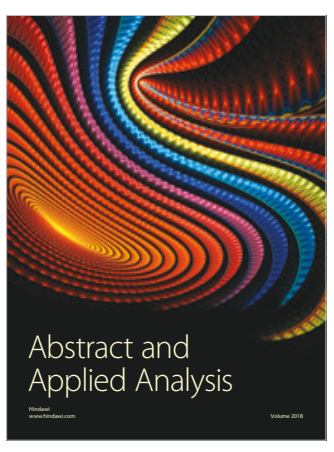

The Scientific

World Journal

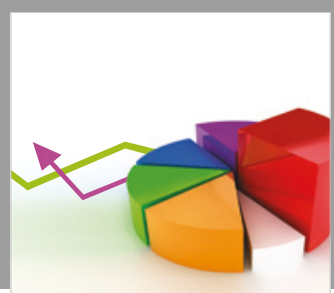

Journal of

Probability and Statistics
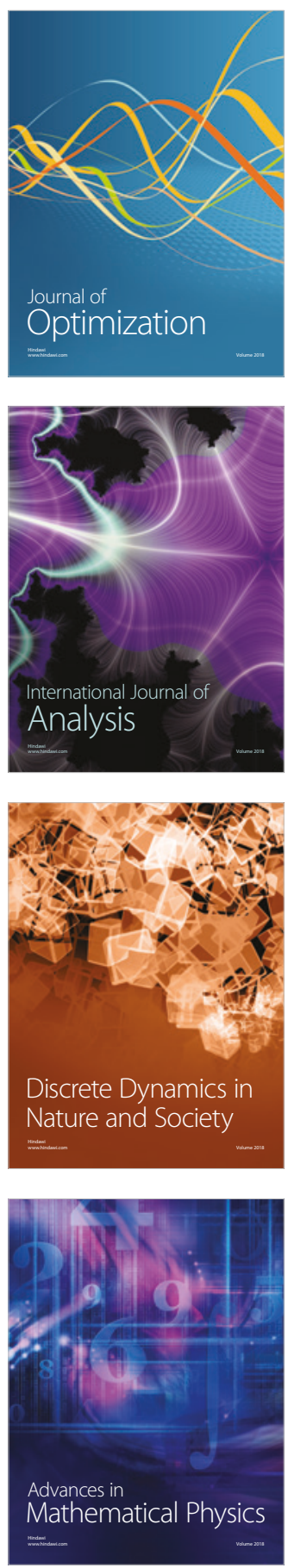